بررسى تأثير روشهاى تغذيه آلى و شيميايى بر ويزّكىهاى كمّى علوفه و دانه ارزن در شرايط تنش خشكى انتهاى فصل (Panicum miliaceum L.)

\author{
ياسر اسماعيليان
}

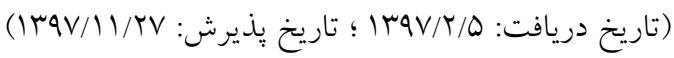

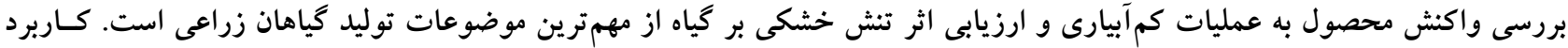

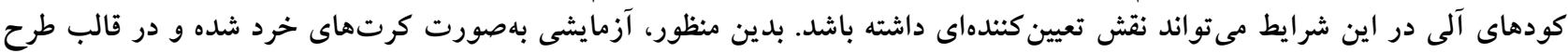

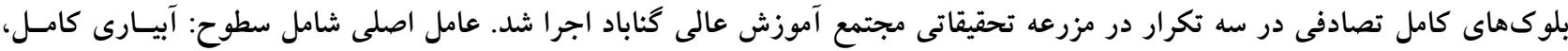

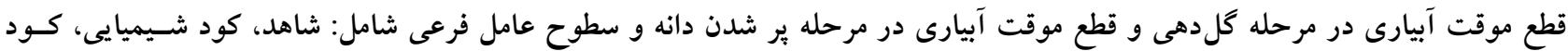

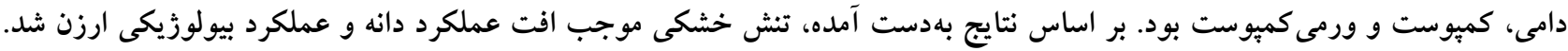

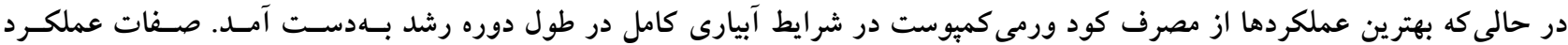

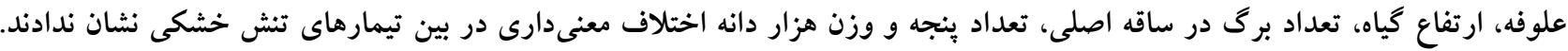

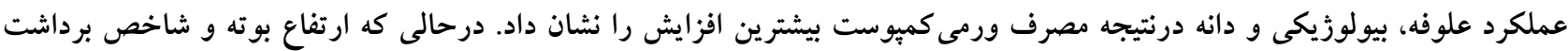

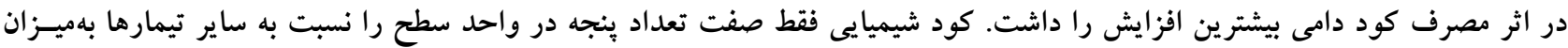

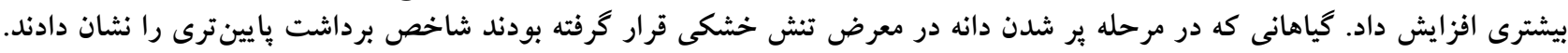

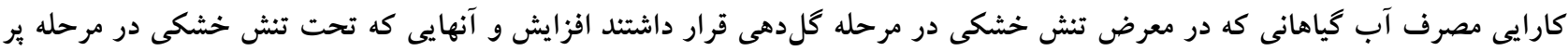

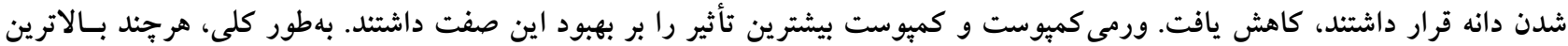

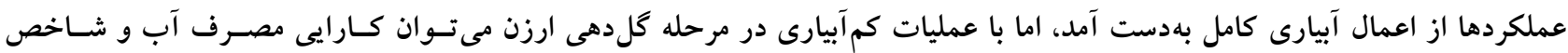

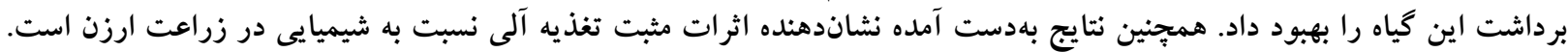

وازههاى كليدى: آبيارى، عملكرد، كارايى مصرف آب، كميوست، كود شيميايى، ورمى كميوست 
كاهش خود در اثر تنش خشكى موجب افت عملكرد ايسن كيـاه

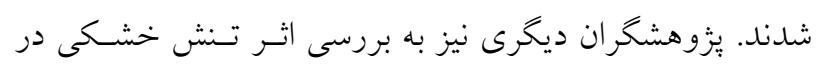

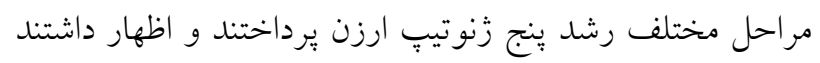

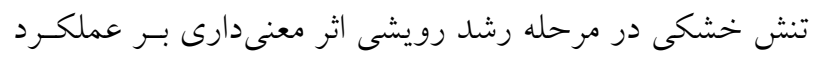

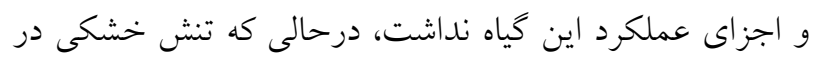

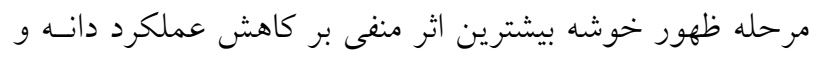
كارايى مصرف آب آن داشت (अq).

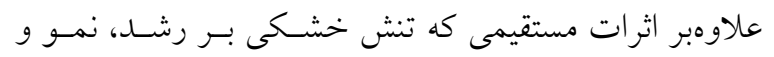

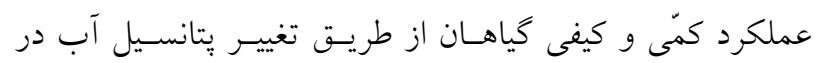
خاك و اختلال در فعاليتهاى بيوشيميايى و فيزيولوزيكى كيــاه

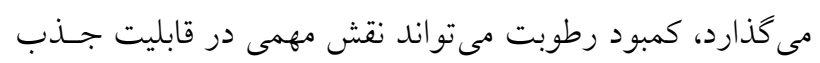

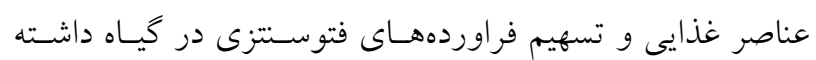

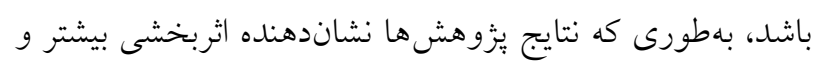

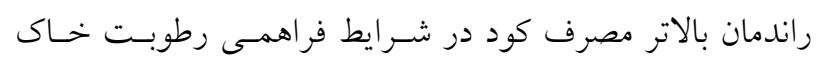

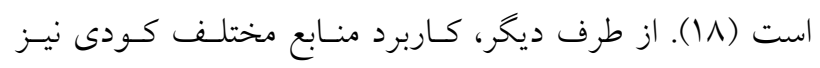

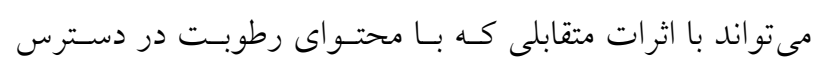

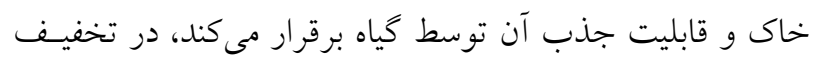

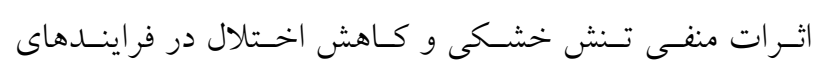

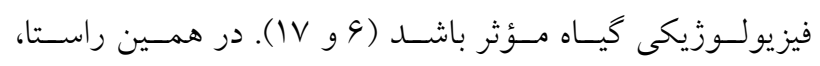

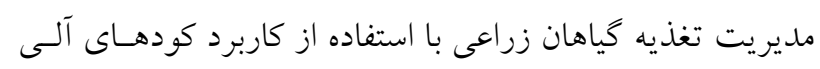

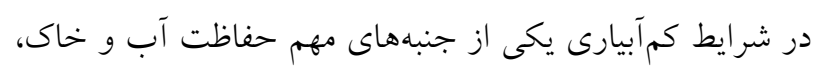

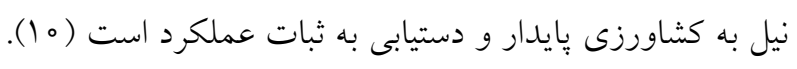

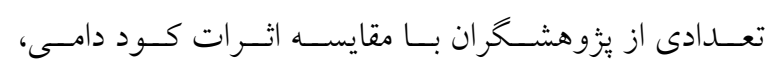

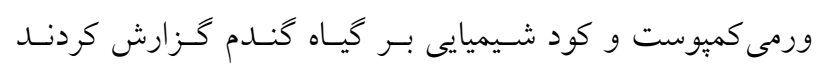

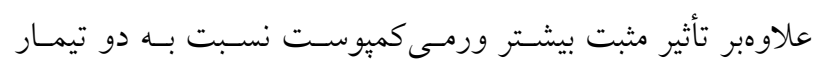

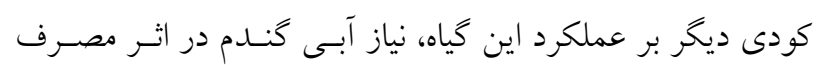

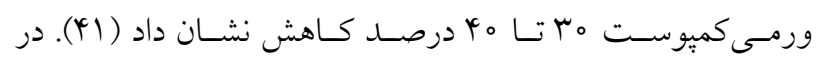

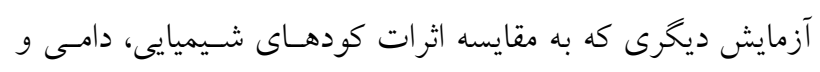

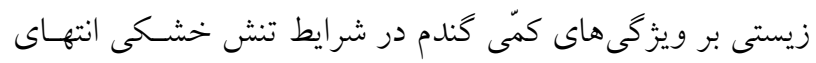

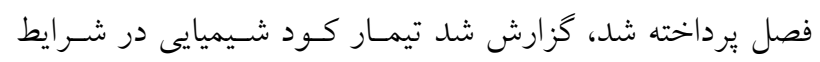

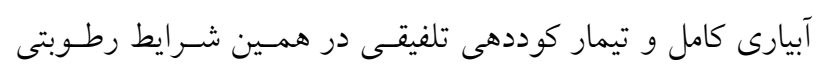

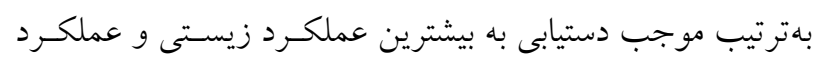

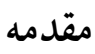

در حال حاضر، تنش خشكى بهدليل تغييرات اقليمسى، گرمـايش

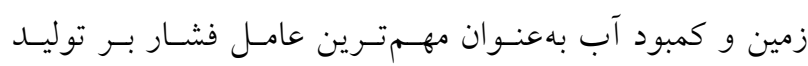

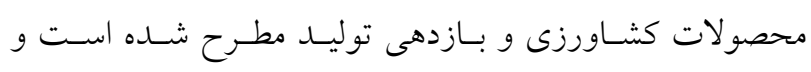

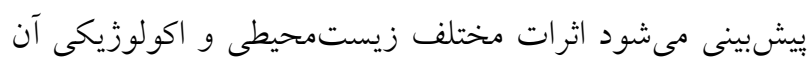

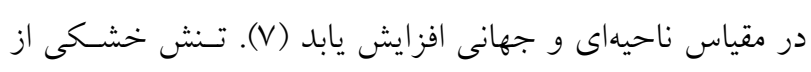

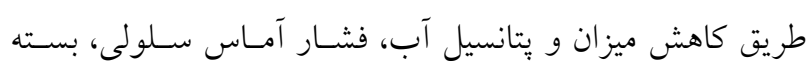

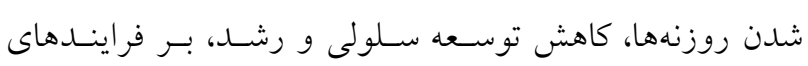

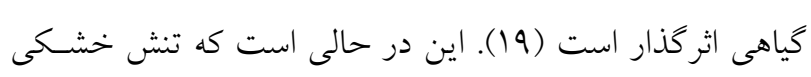

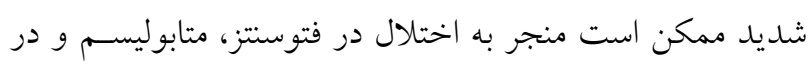

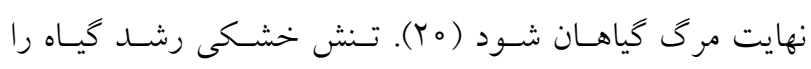

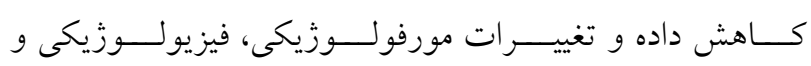

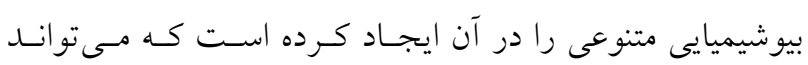

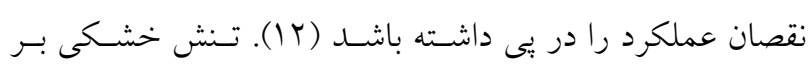
اساس اينكه در جهه سطحى از محتـواى رطوبـت خهـاك اعمـال

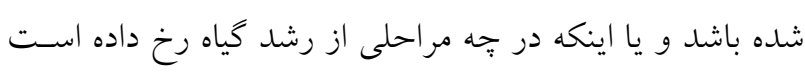

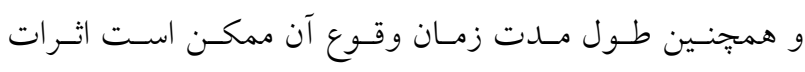

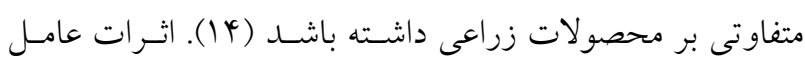

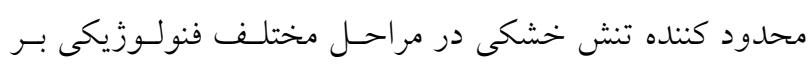

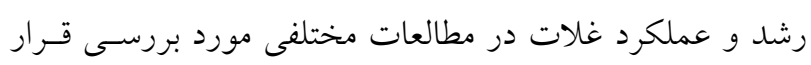

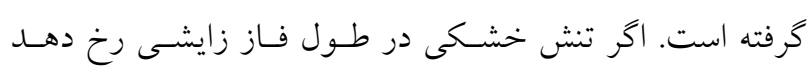

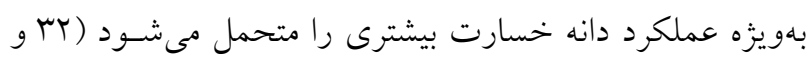

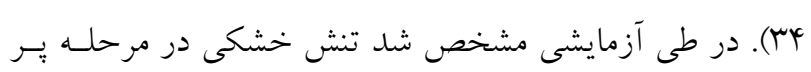

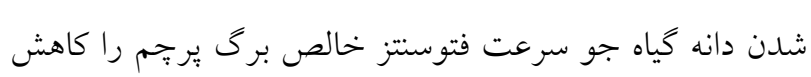

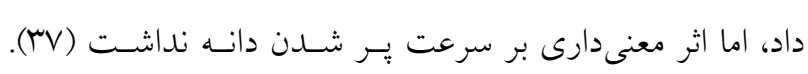

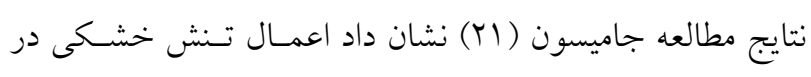

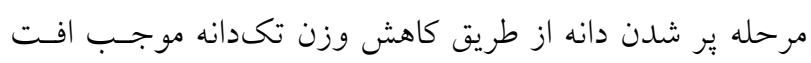

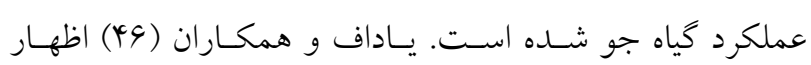

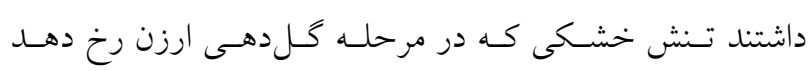

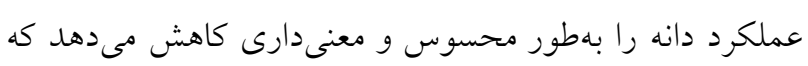

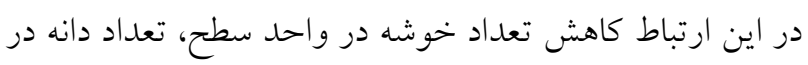

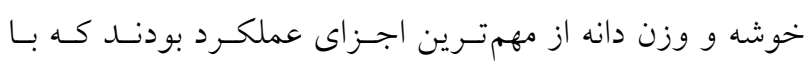




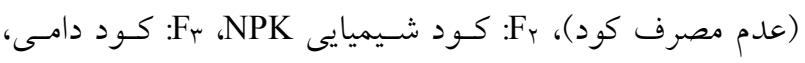

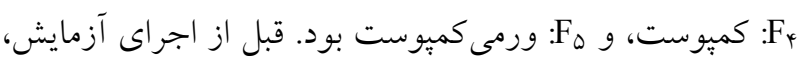

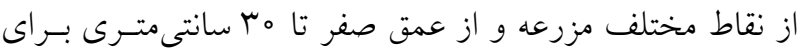

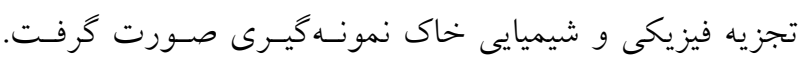

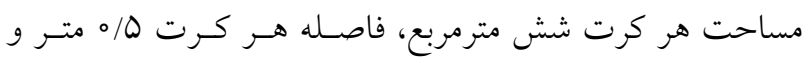

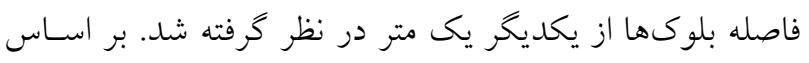

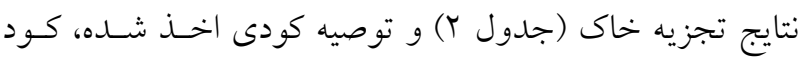

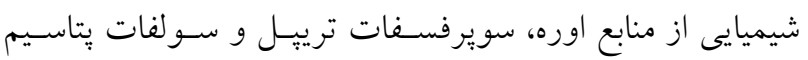

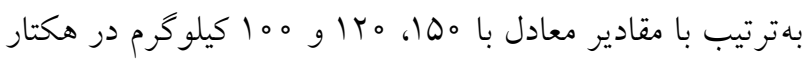

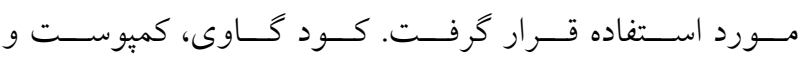

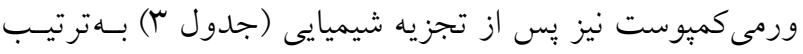

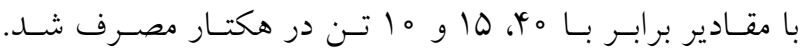
كودهاى آلى و شيميايى (00 درصد كود اوره) مورد استفاده در

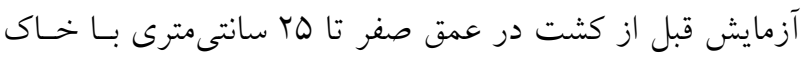

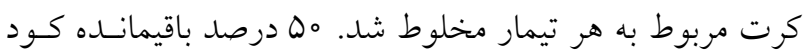

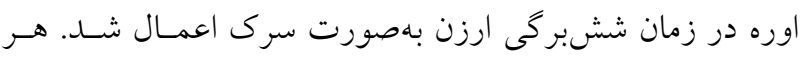
كرت شامل ه ا رديف كاشت به طول دو متـر و بــا فاصـله بسين

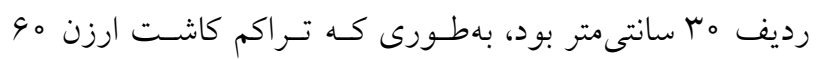

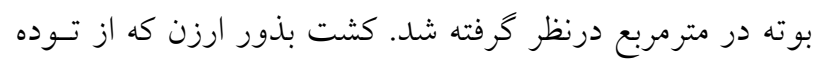

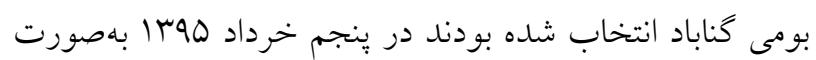

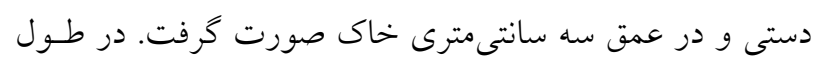

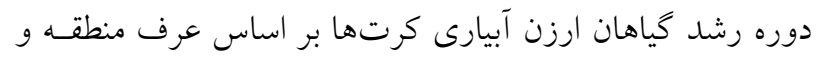

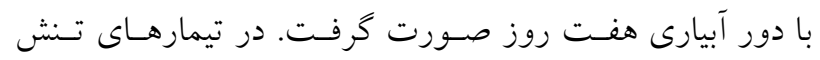

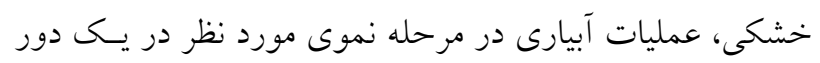

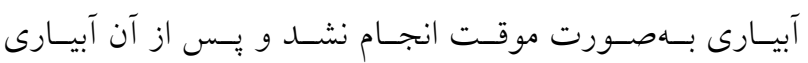

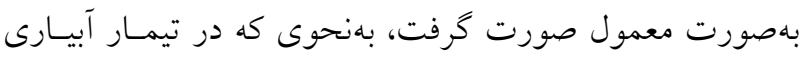

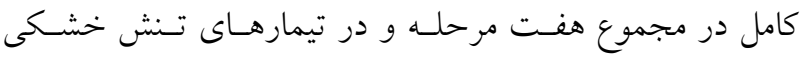

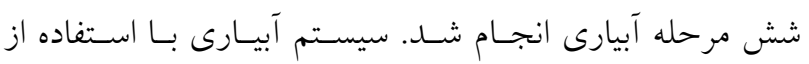

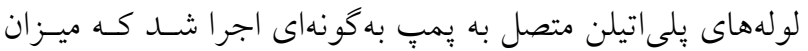

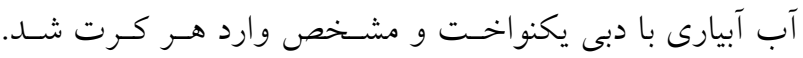
ساير عمليات داشت شامل بر وجين علفهاى هرز بــراى تمـام كرتها تمام كرتها بهصورت يكسان انجام شد.
دانه در كندم شد، اما كاربرد بهتنهايى و بهويزه توأم كودهاى دامى و زيستى اثر قابل توجه و معنى دارى در ثبات عملكـرد ايسن كيـاه

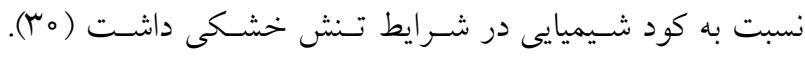

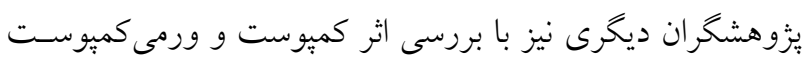

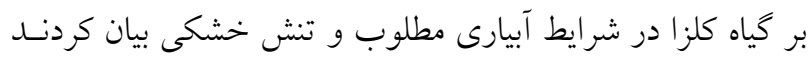

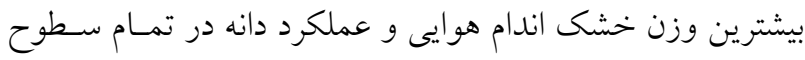

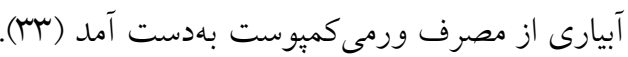

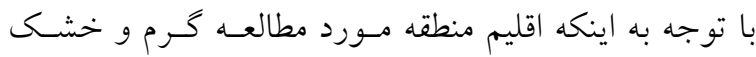
بوده و محدوديت منـابع آب آبيـارى و همجِنسين تــاخل زمهـان

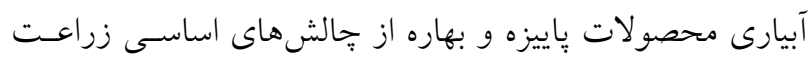
در منطقه است، مديريت و صرفهجويى در مصـرف آب و ارائسه

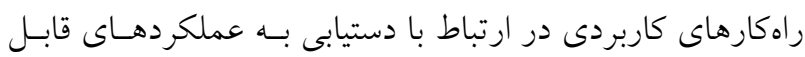
قبول و كاهش اثرات منفى تنش خشكى بر رشد، نمو و عملكرد

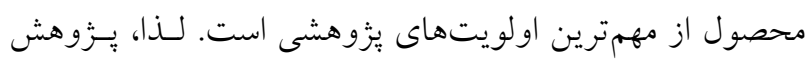

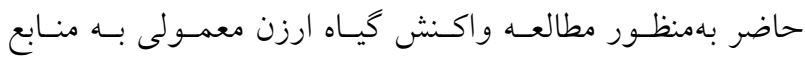
مختلف كودهاى آلى و شيميايى در شرايط تنش خشكسى ناشسى

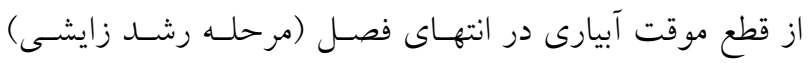

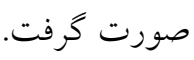

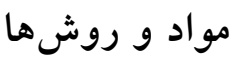

اين آزمايش بهصورت كرتهاى خــرد شـده و در قالـب طـرح

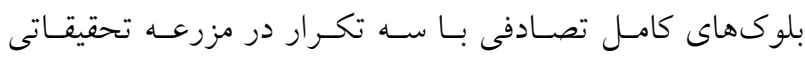

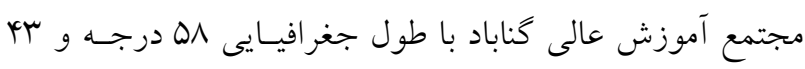

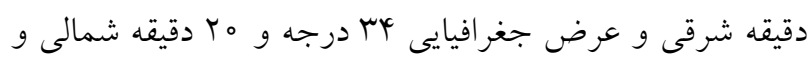

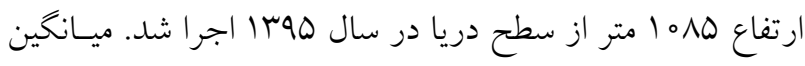
درجه حرارت منطقه IV/T درجه سانتى كراد و بارندكى سـاليانه

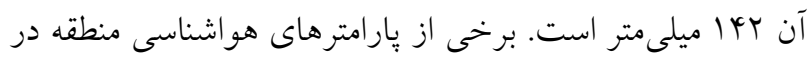

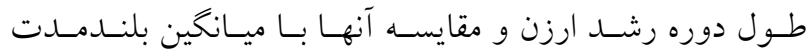

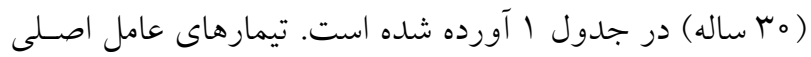
شامل: D, آبيارى كامل در طول فصل رشــد،

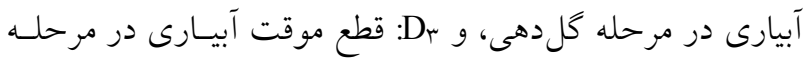

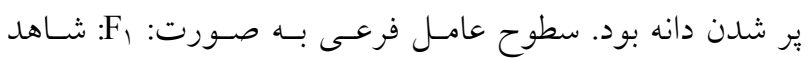


جدول ا. برخى بارامترهاى هواشناسى منطقه در طول دوره رشد ارزن و مقايسه آن با ميانخين بلندمدت

\begin{tabular}{|c|c|c|c|c|c|c|c|c|c|}
\hline بارندكى & بلندمدانكين & رطوبت نسبى & بلندمدت & رطوبت نسبى & بلندمانكين & حرارت & ميلندمدت & حرارت حراقل & ماه \\
\hline (ميلى متر) & & \multicolumn{3}{|c|}{ (درصد) } & \multicolumn{4}{|c|}{ (درجه سانتى گراد) } & \\
\hline$r / Q$ & $\mu$ & rq & 19 & 9 & $r</ 4$ & $r \Delta / \Lambda$ & $r \circ / \Gamma$ & $r / N$ & خرداد \\
\hline 。 & ז & m & 10 & $1 r$ & $r 9 / V$ & $r q / 1$ & $r Y / Q$ & $r Y / 9$ & تير \\
\hline 。 & r。 & rr & 14 & 11 & $r \Delta / v$ & $r \Delta / 9$ & ro/A & $r \mid r$ & مرداد \\
\hline
\end{tabular}

جدول r. ويزّى هاى فيزيكى و شيميايى خاك محل آزمايش

\begin{tabular}{|c|c|c|c|c|c|c|c|c|c|}
\hline \multirow{2}{*}{ اسيديته } & هدايت الكتريكى & قُبابل جذب & قابل جذب & نيتروزن كل & كربن آلى & 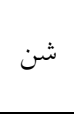 & سيلت & رس & \multirow{2}{*}{ بافت خاك } \\
\hline & متر ) مسيس بر & \multicolumn{2}{|c|}{ (ميلى كرم بر كيلو كرم) } & \multicolumn{5}{|c|}{ (درصد) } & \\
\hline$N / T$ & $\mu \mu$ & lor & $\wedge$ & $0 / 019$ & $0 / 19$ & $\Delta r / 4$ & 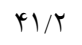 & $\Delta / 4$ & لومى ششنى \\
\hline
\end{tabular}

جدول r. ويزگى هاى شيميايى كودهاى آلى مورد استفاده

\begin{tabular}{|c|c|c|c|c|c|}
\hline \multirow[b]{2}{*}{ اسيديته } & هدايت الكتريكى & يتاسيم & فسفر & نيتروزن & \multirow[b]{2}{*}{ نوع كود } \\
\hline & (دسىزيمنس بر & \multicolumn{3}{|c|}{ (درصد) } & \\
\hline$V / r$ & $r / 9$ & $0 / 9$ & $\circ / V$ & $T / Y$ & كود كاوى \\
\hline $\mathrm{V} / \mathrm{\Lambda}$ & $Q / Y$ & $1 / \Lambda$ & $1 / 0$ & $1 / \pi$ & كميوست \\
\hline$\Lambda / Y$ & $9 / 9$ & $1 / \Lambda$ & $1 / 0$ & $1 / N$ & ورمى كميوست \\
\hline
\end{tabular}

يكى مترمربع وسط هر كرت برداشت و يّ از هواخشك كردن،

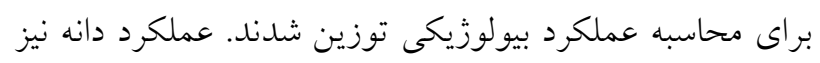

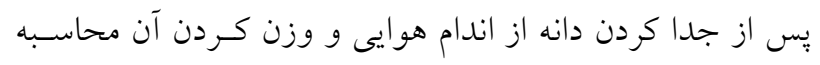

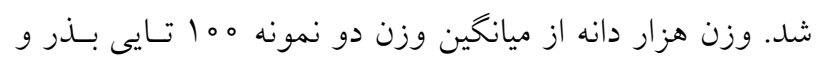

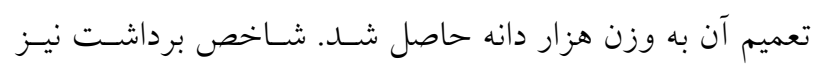
طبق فرمول زير بهدست آمد: $\mathrm{HI}=\frac{\mathrm{EY}}{\mathrm{BY}} \times 1 \circ$ 。

كـه در معادلـه فـوق HI شـاخص برداشـت (Harvest index)، EY عملكرد اقتصادى (Economic yield) كه در اينجا عملكرد

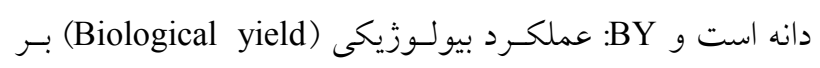

عملكرد علوفه تر در شروع كل دهى با برداشت كل اندام هـو اييى

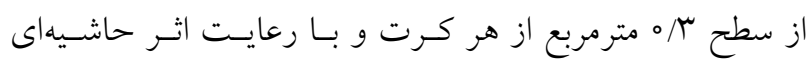

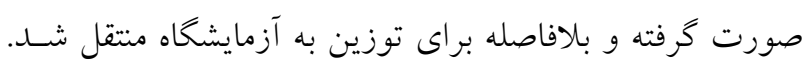

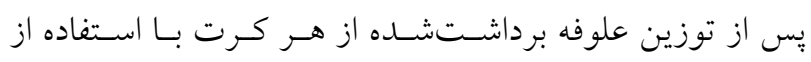

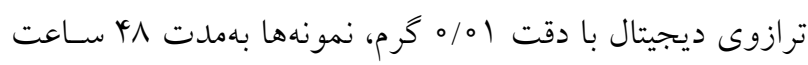

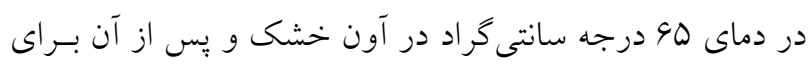

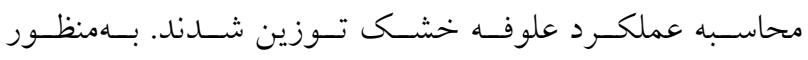

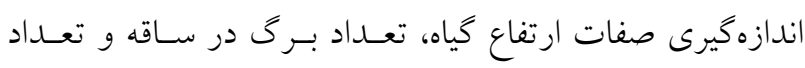

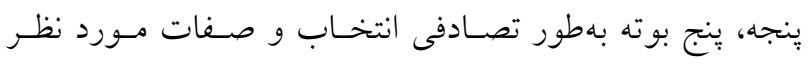

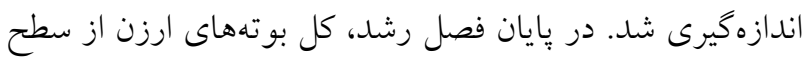


اثر سطوح تنش خشكى بر عملكرد علوفه تر را مى توان به اين

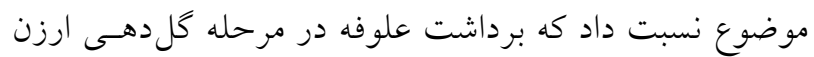

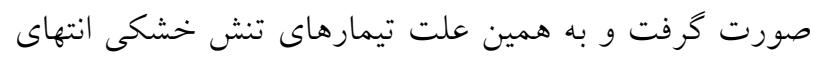

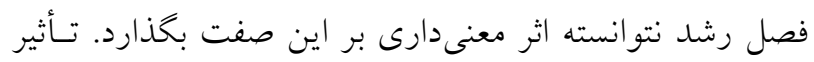

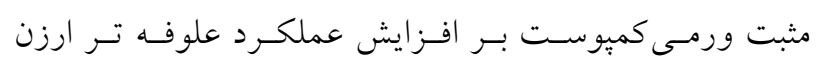

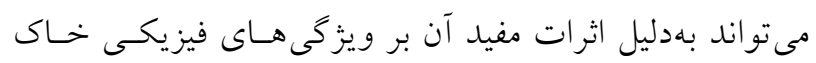

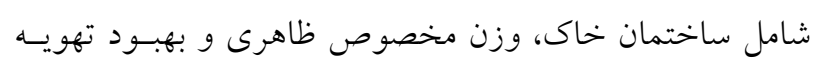

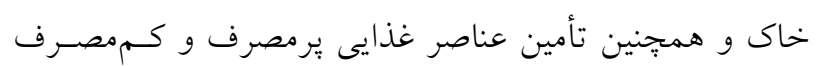

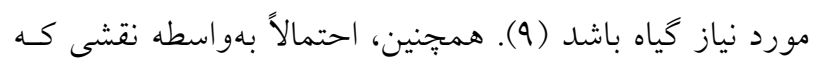

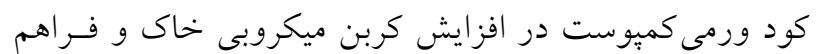

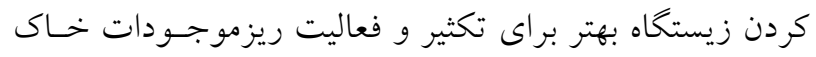

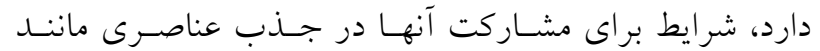

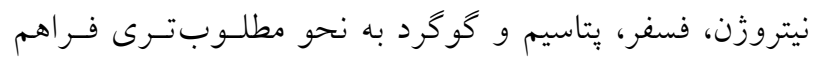

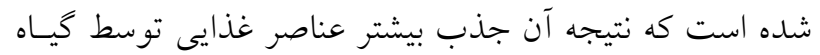

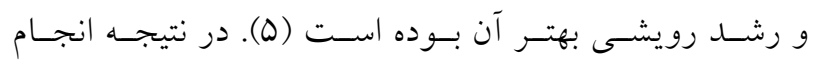

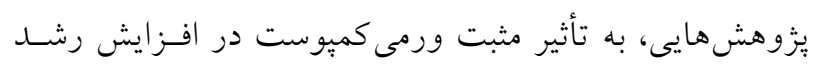

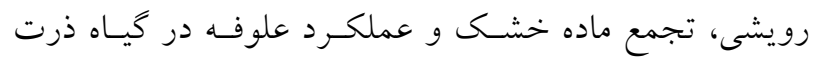
(19) و جو (Yr) اشاره شده است.

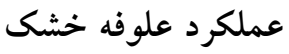

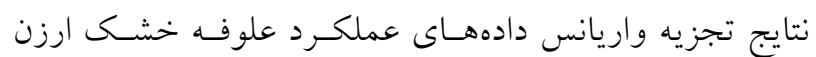

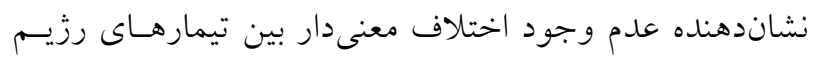

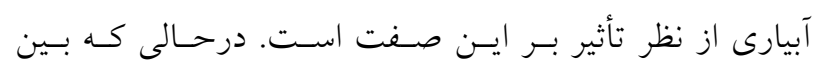

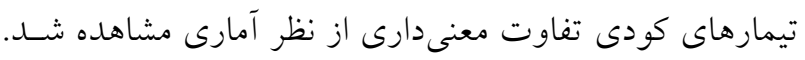

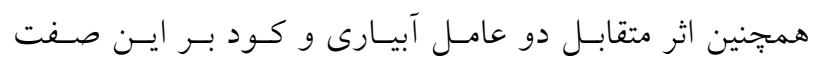

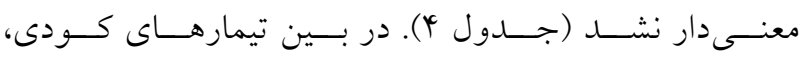
ورمى كميوست با IVo9 كيلـو گرم در هكتـار علوفـه خشك بيشترين تأثير را بر بهبود اين صـفت داشـت. تيمارهـاى كـود شيميايى و كميوست به صـورت مشـترك در رده بعـدى قـرار

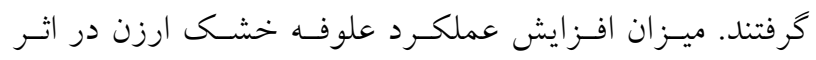
مصرف ورمى كميوست نسبت به تيمار علم مصسرف كـود FV درصد بود (جدول ه).
اساس وزن ماده خشك توليدى است. كـاريى مصـرف آب نيـز توسط فرمول زير محاسبه شد:

$\mathrm{WUE}=\frac{\mathrm{D}}{\mathrm{W}_{\mathrm{p}}+\mathrm{W}_{\mathrm{i}}}$

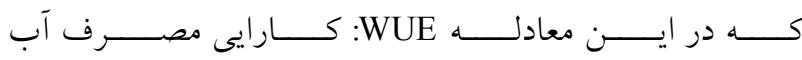
(Water use efficiency) كيلـو گرم مــاده خشـك دانــه در هكتـار)، Wp: آب حاصـل از بارندگى و Wi: آب حاصل از آبيارى (بر مبنـاى متـرمكعبب در هكتار) است. با توجه به اينكه در طول دوره رشد گياهـان ارزن بارندگى در منطقه رخ نداد، كارايى مصرف آب براى هـر تيمـار

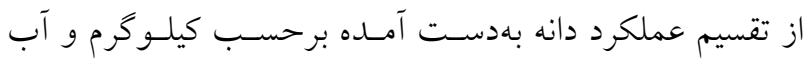
آبيارى مصرفشده برحسب مترمكعب در هر كرت محاسبه شد. درنهايت، دادههاى بهدست آمده با اسـتفاده از نـرمافـزار آمـارى نسخه 9 تجزيهو تحليل آمارى شد و مقايسه ميانخينها نيـز بر اساس آزمـون حسداقل اخـتلاف معنسى دار (LSD) در سـطح احتمال ينج درصد صورت گرفت. براى رسـم نمودارهـا نيـز از نرمافزار Excel استفاده شد.

\section{نتايج و بحث} عملكرد علوفه تر تجزيه واريانس دادههاى عملكرد علوفه تر ارزن نشان داد اتـر تيمارهاى تنش خشكى بر اين صفت معنىدار نبود. درحالى كه كودهاى آلى و شيميايى اثر معنى دارى در سـطح احتمـال يـنج درصد بر آن داشـتند. همجنهـين، اثـر متقابـل تيمارهـاى تـنش خشكى و كودى بر صفت مذكور معنى دار نشد (جدول \&). بر اساس نتايج مقايسه ميانكين دادهها، بيشترين عملكرد علوفه تر

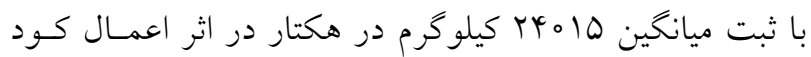
ورمى كميوست بهدست آمــد. سـاير تيمارهـاى كـودى از نظـر آمارى اختلاف معنى دارى بــا يكـديخر نشـان نــاد و در رتبـهـ بعدى قرار كرفتند، درحالى كـهـ كمتـرين عملكــرد علوفـه تـر

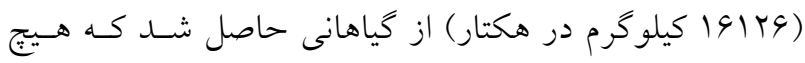
كودى دريافت نكرده بودند (جدول ه). علت معنسىدار نشــن 


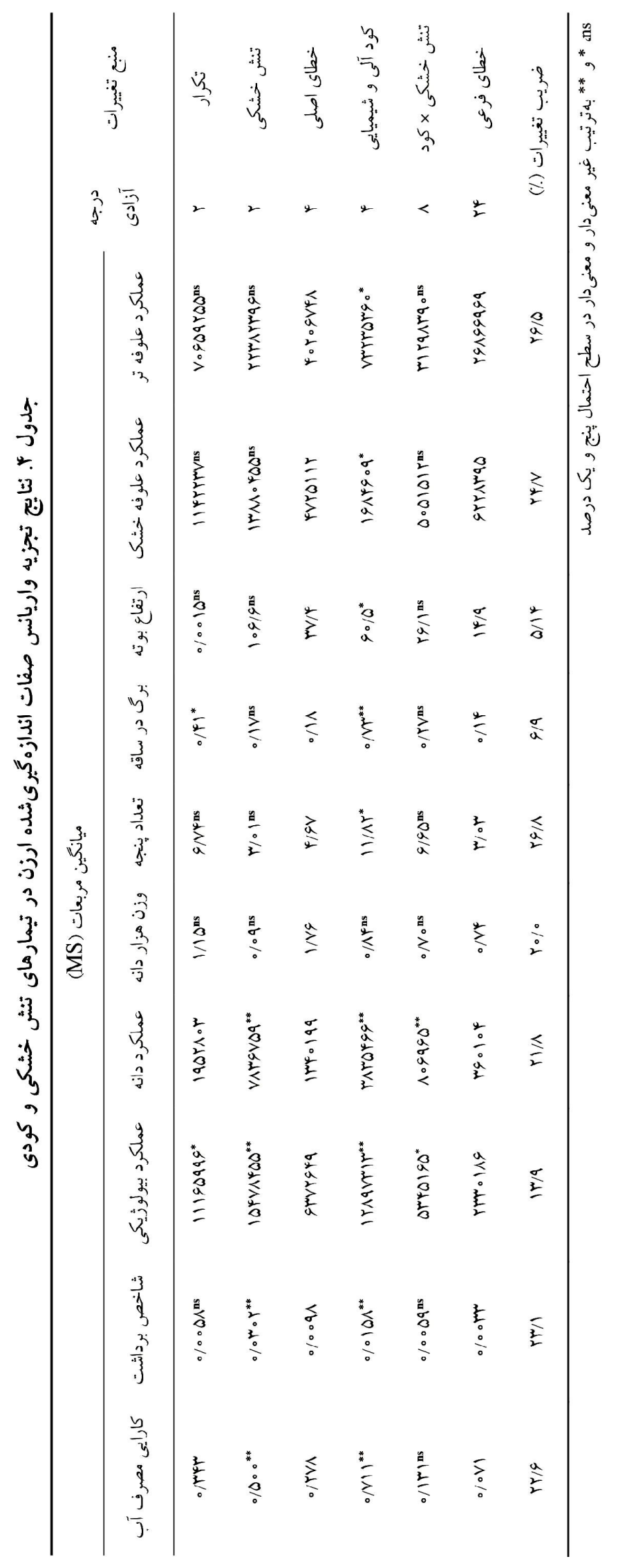




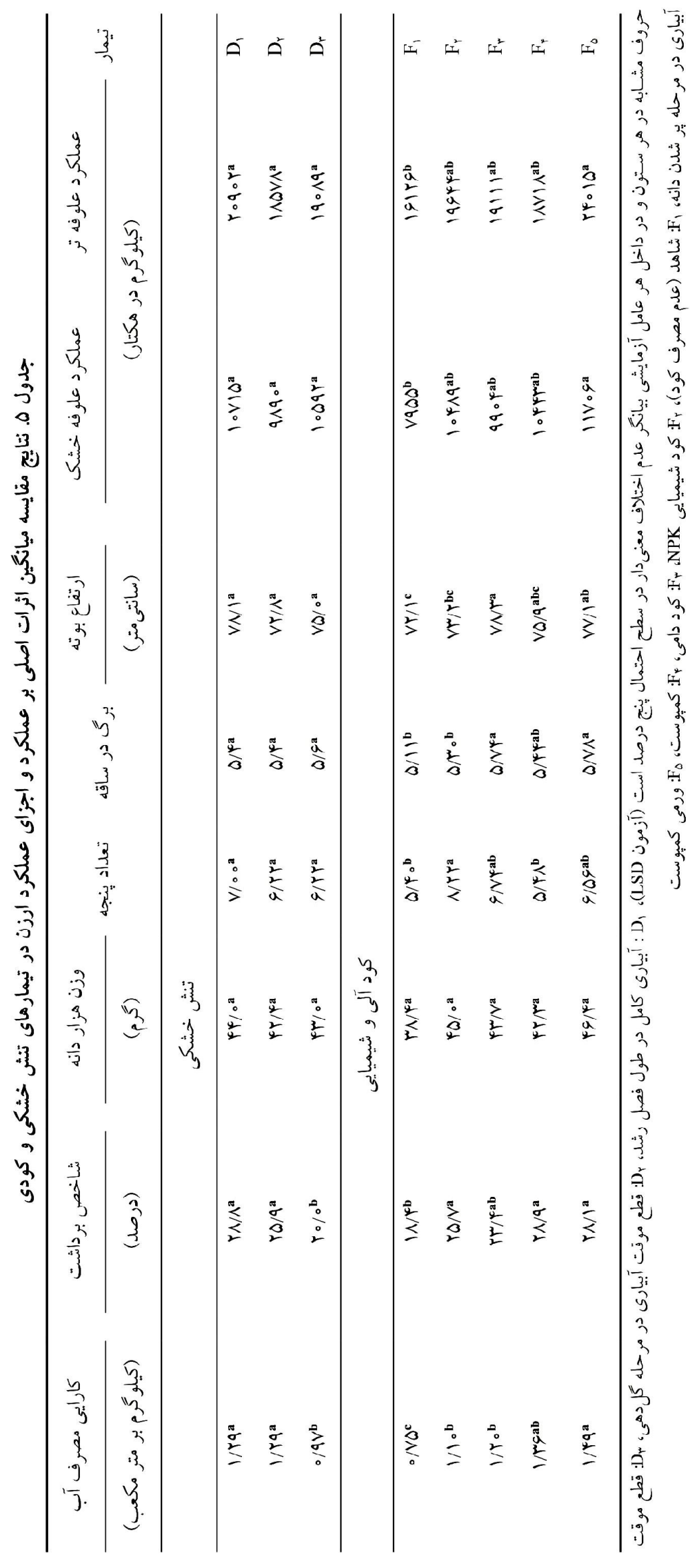


نفوذيذيرى و افزايش ظرفيت نخهدارى آب در خاك، موجـب

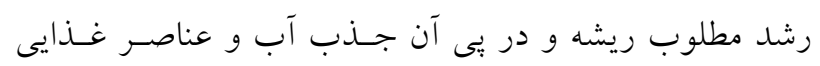

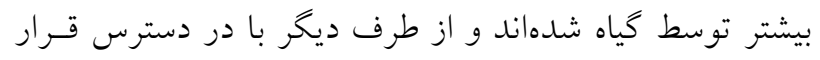

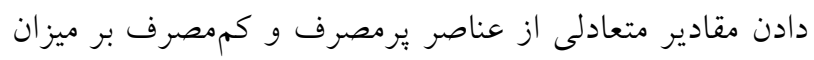

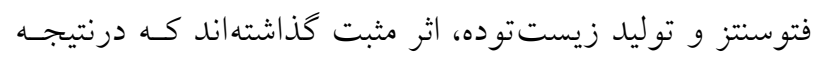
اثر خود را بهصورت افزايش ارتفاع بوته نشــان دادهانــ (سبا).

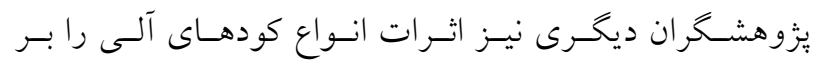

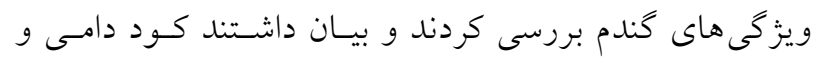

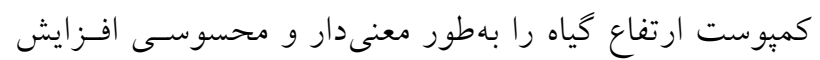
دادند (4) (4)

\section{تعداد برى در ساقه اصلى - ملى}

جدول تجزيـه واريـانس دادههـاى آزمـايش بيـانكر عـدم اخـتلاف

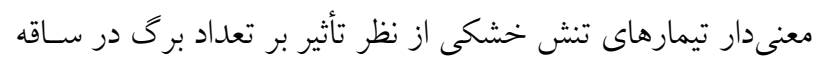
اصلى است. اما، بين منابع مختلف كودهاى آلى و شيميايى در مـورد

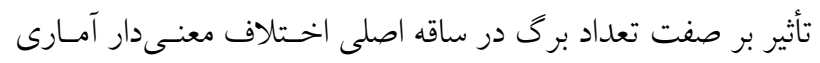

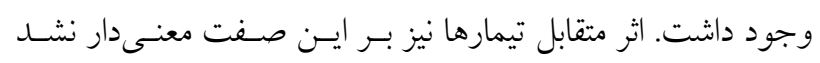

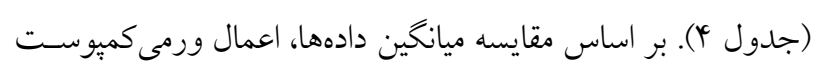

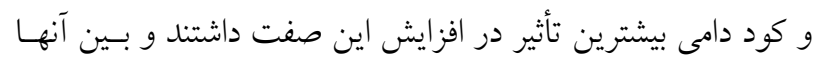

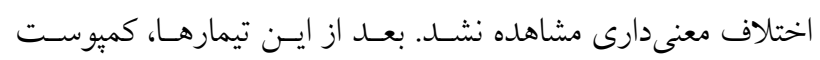

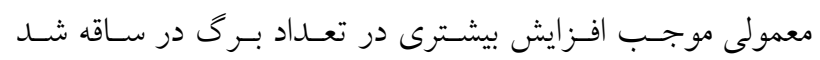

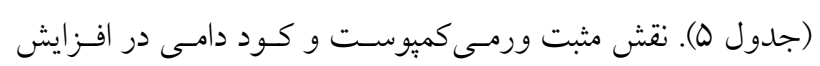

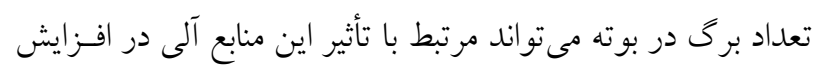

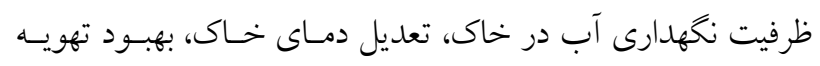

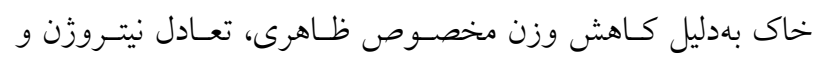

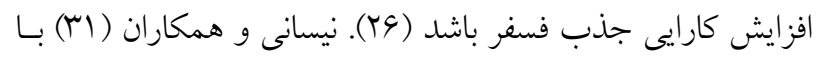

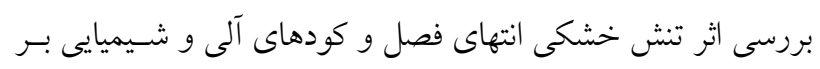

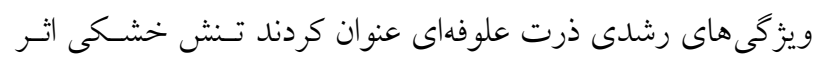

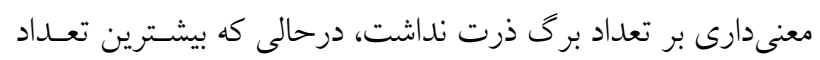

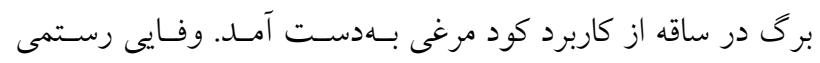

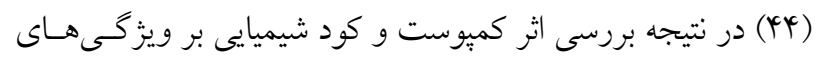

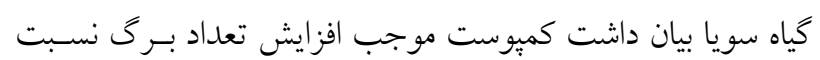

علت اين افزايش عملكرد را مىتوان به بهبود شرايط فيزيكى،

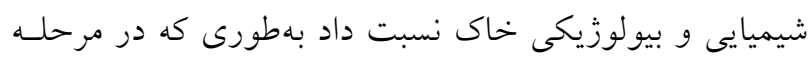

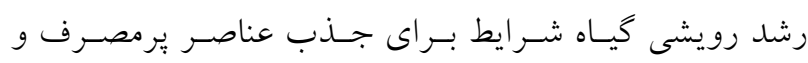

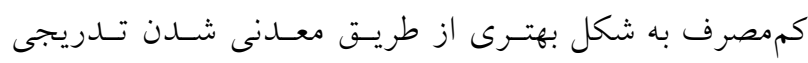

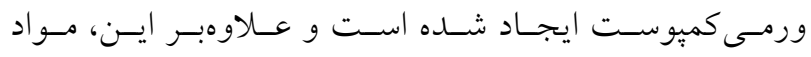

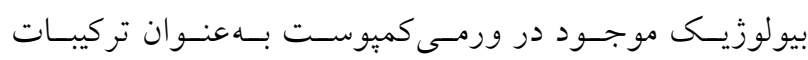

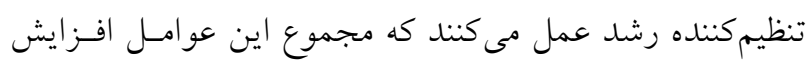

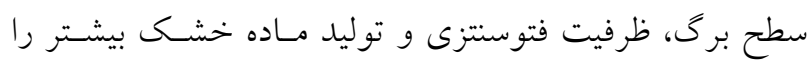

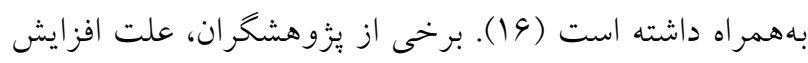
رشد رويشى و زيست توده زنــده محصـول در نتيجـهـ كـاربرد

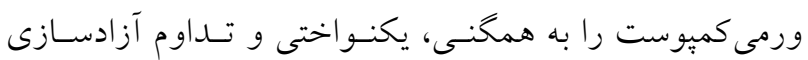

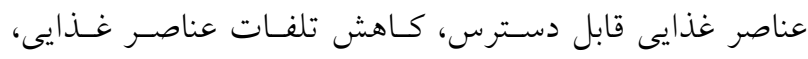

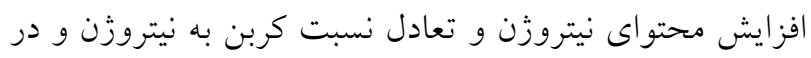

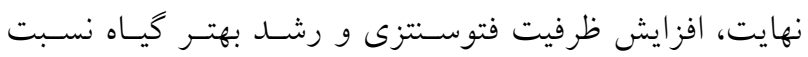

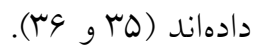
ارتفاع گیاه

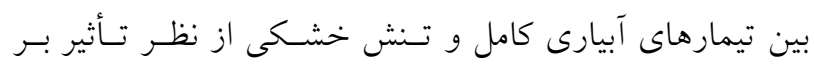

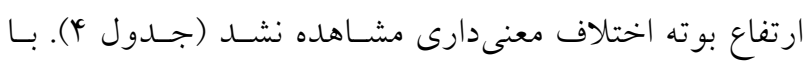

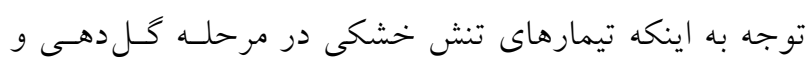

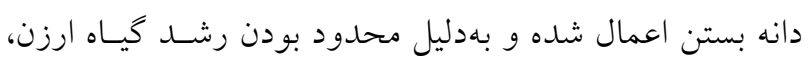

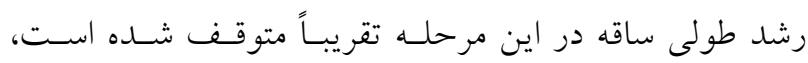
بنابراين نتايج بهدست آمده قابل انتظار است. بر اسـاس نتس نـايج

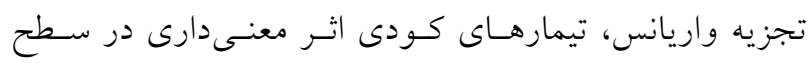

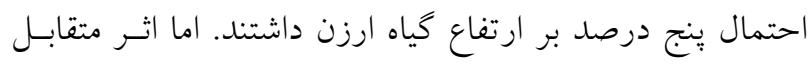

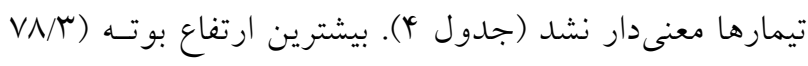

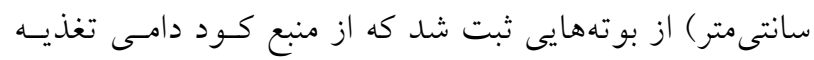

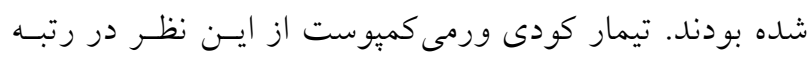

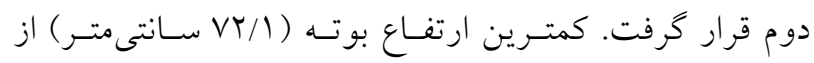

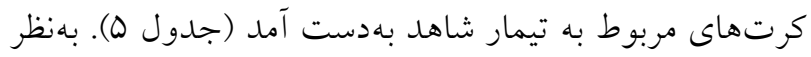

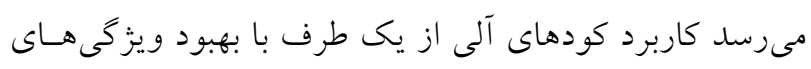

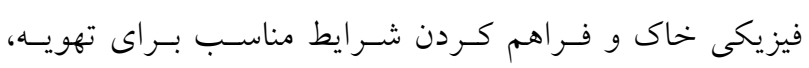


اختلاف معنى دارى وجود نداشت. اثر متقابـل دو عامـل تـنش به كاربرد كود شيميايى شد.

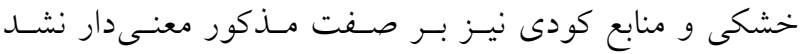

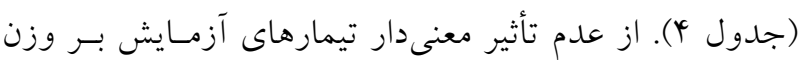

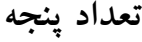

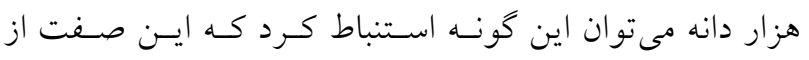

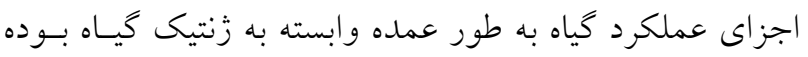

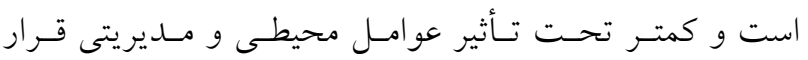

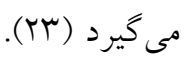

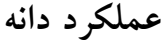

اختلاف بين تيمارهاى تنش خشكى از نظر تأثير بر عملكرد دانه

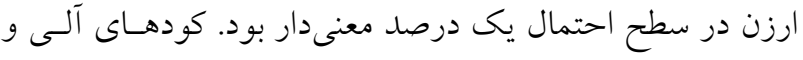

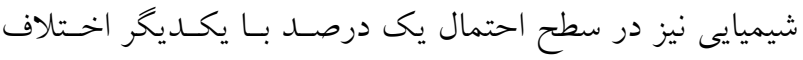

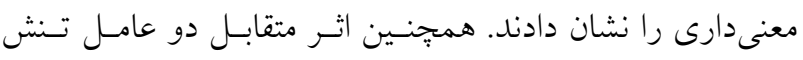

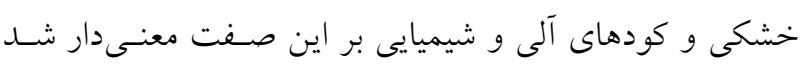

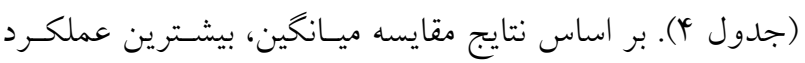

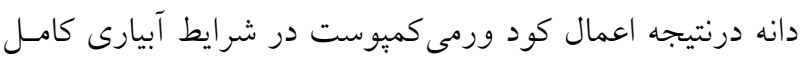
بهدست آمد و يس از اين تيمار نيز بهترتيب تيمارهـاى مصسرف

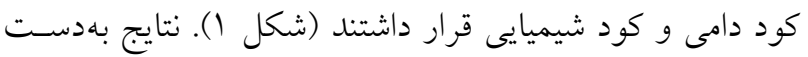

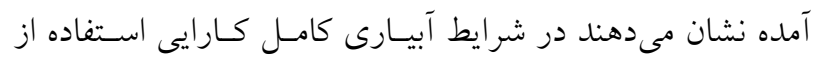

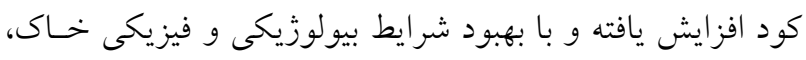

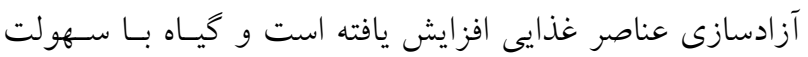

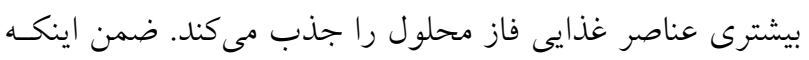
كميوست علاوه بر دارا بودن مقــادير قابـل تـوجهى از عناصـر فئرس مـاكرو (بـهـويـزّه نيتــروزن)، حساوى مقـادير زيـادى تركيبـات

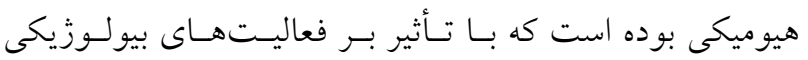

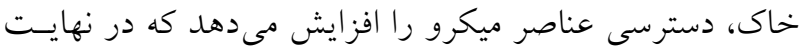

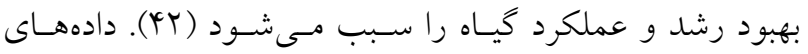

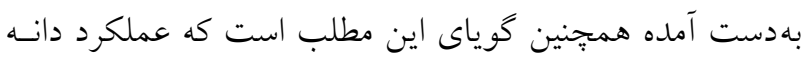
كياهان ارزن كوددهى شده در شرايط تنش خشكى بلميزان قابل

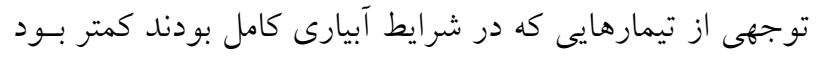

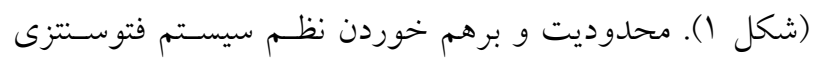

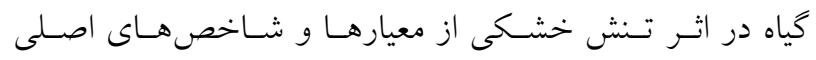

بين سطوح عامل تنش خشكى از نظر تأثير بر تعداد بنجه در گيـاه

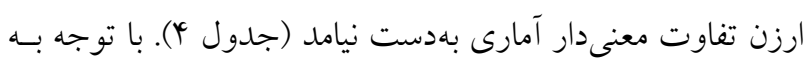

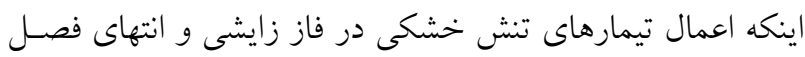

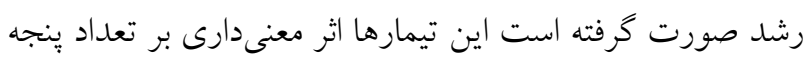

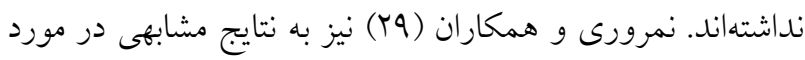
كياه كَندم دست يافتهاند. تجزيهوتحليـل آمـارى دادهــاى تعـداد

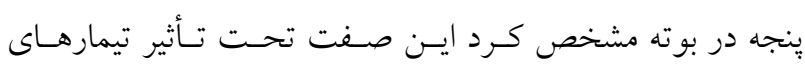
كودى اختلاف معنى دارى نشان داد. درحالى كه اثر متقابل تيمارها

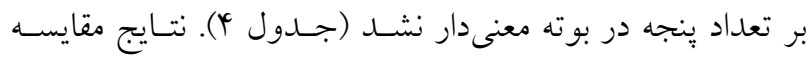

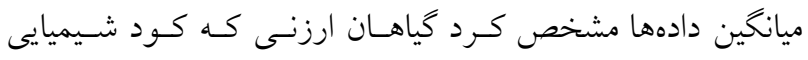

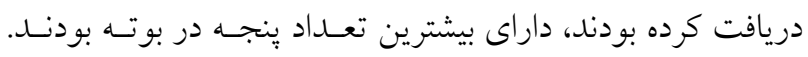

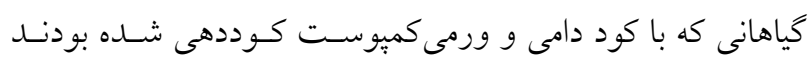

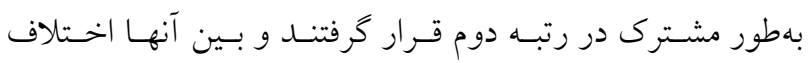

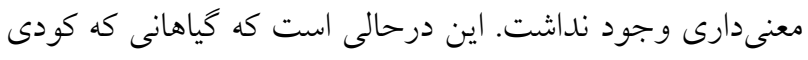

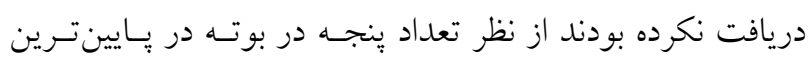

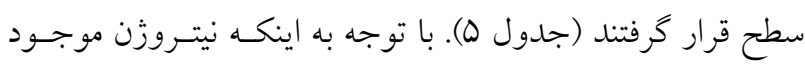

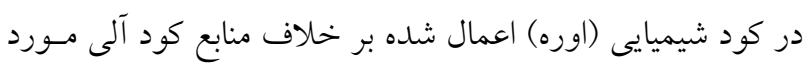
استفاده به سرعت آزاد شده و بهصورت تركيبات نيتراتى وارد فـاز

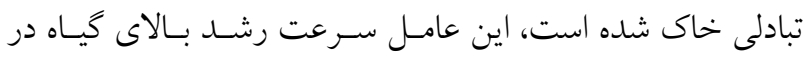

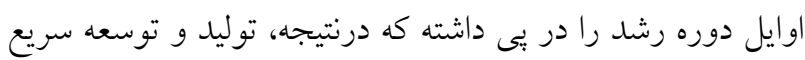

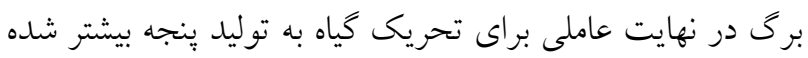

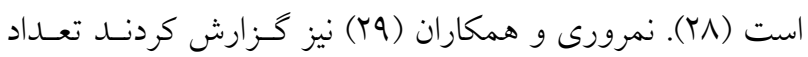
ينجه در بوته گُندم در اثر مصرف كود شسيميايى نسبت بـهـ كـود دامى و بيولوزيك افزايش بيشترى نشان داد.

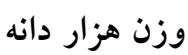

صفت وزن هزار دانه ارزن تحت تأثير تيمارهاى تنش خشكى دانه

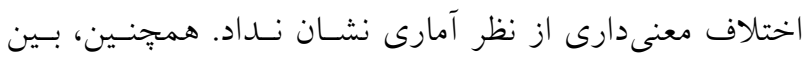

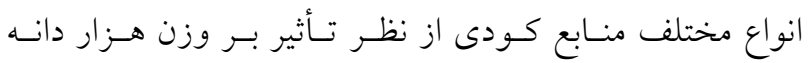




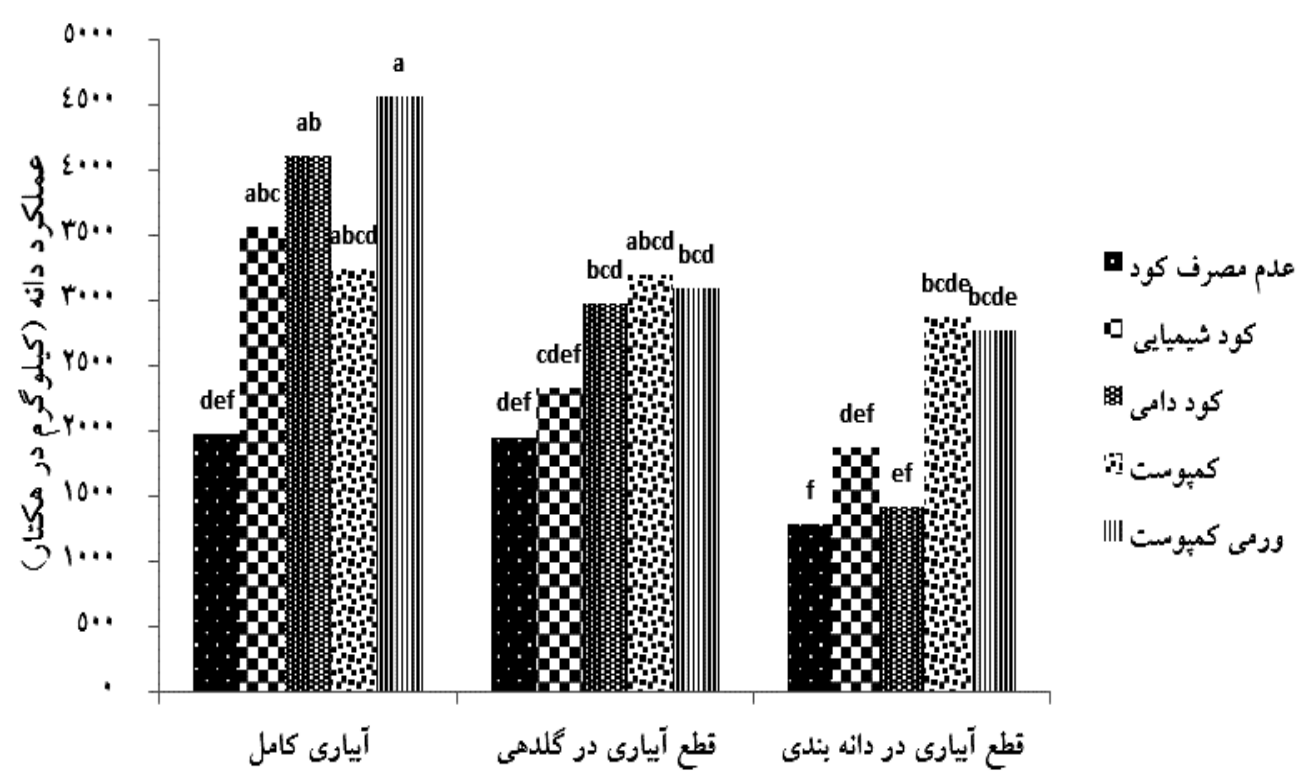

شكل ا. برهم كنش تيمارهاى تنش خشكى و كودى بر عملكرد دانه ارزن. ستونهاى داراى حروف مشابه نشاندهنده عدم وجود اختلاف معنى دار در سطح احتمال ينج درصد هستند (آزمون LSD)

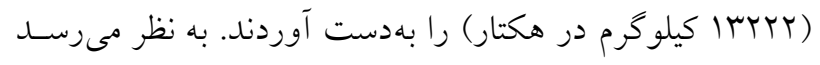

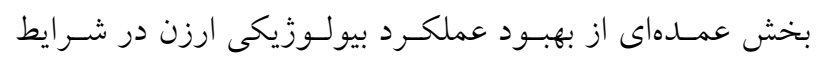

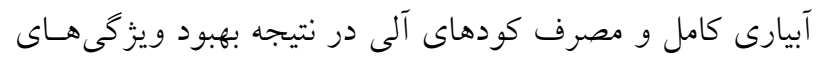

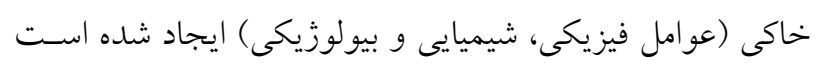

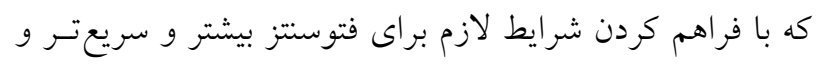

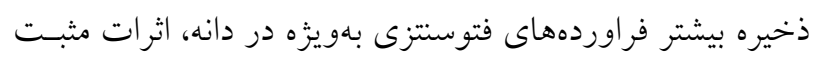

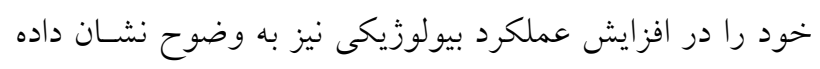

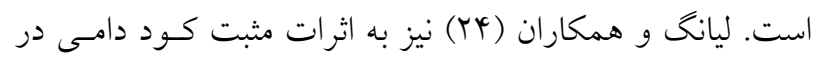

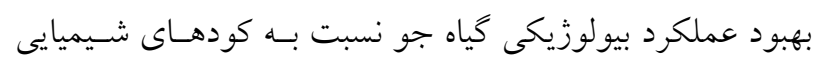

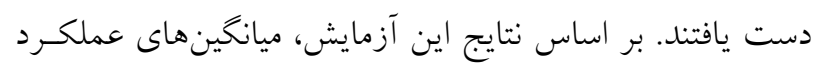

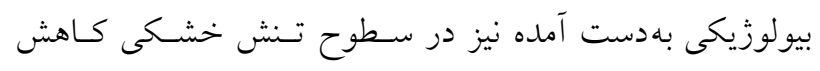

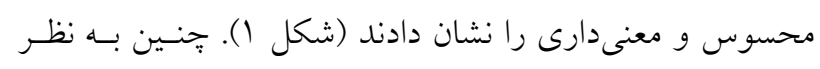

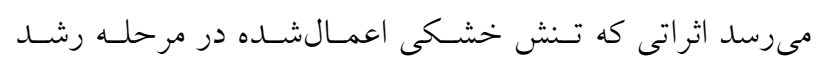
زايشى بر جذب آب و عناصر غذايى، شدت تعـرق و تبـادلات كازى، ظرفيت فتوسنتزى، طول دوره سبزمانى برك كها و به دنبال

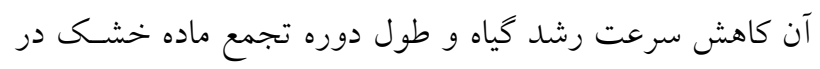

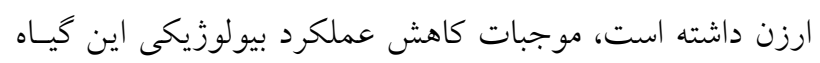

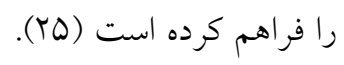

تعيين كننده اثرات تنش خشكى بر رشد، بقا و عملكـرد كياهـان است (1)). در نتيجه يزووهشهاى ديخرى نيز به كاهش عملكرد

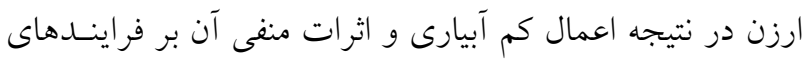
فيزيولوزيكى گياه اشاره شده است (^). عملكرد بيولوزيكى

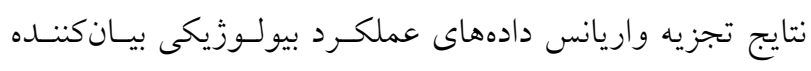

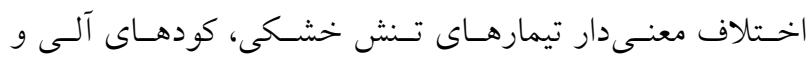

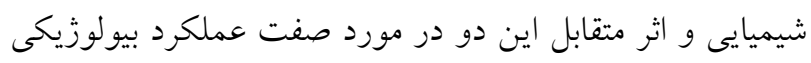

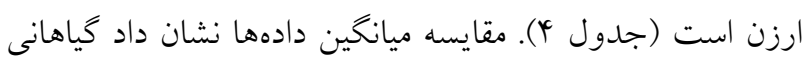

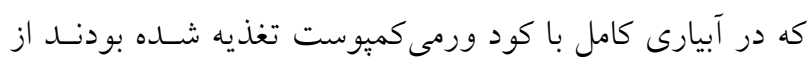

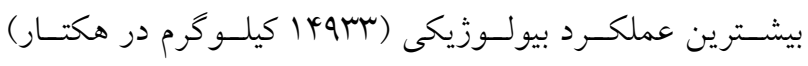

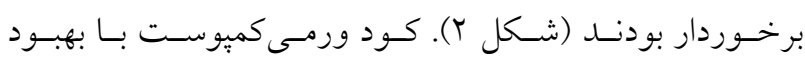
ساختمان خاك و اصلاح ويزّى هاى شيميايى خاك، رشد ريشه را افزايش داد و با افزايش قابليت دسترسى نيتـروزن در شـرايط فراهمى رطوبت كافى در خاك، موجـب اضـافه شــدن بيومـاس

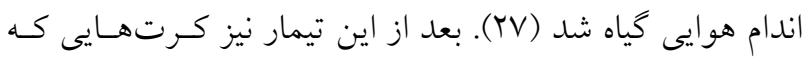

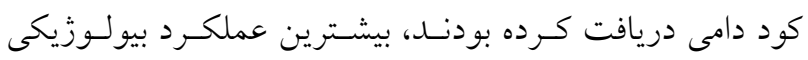




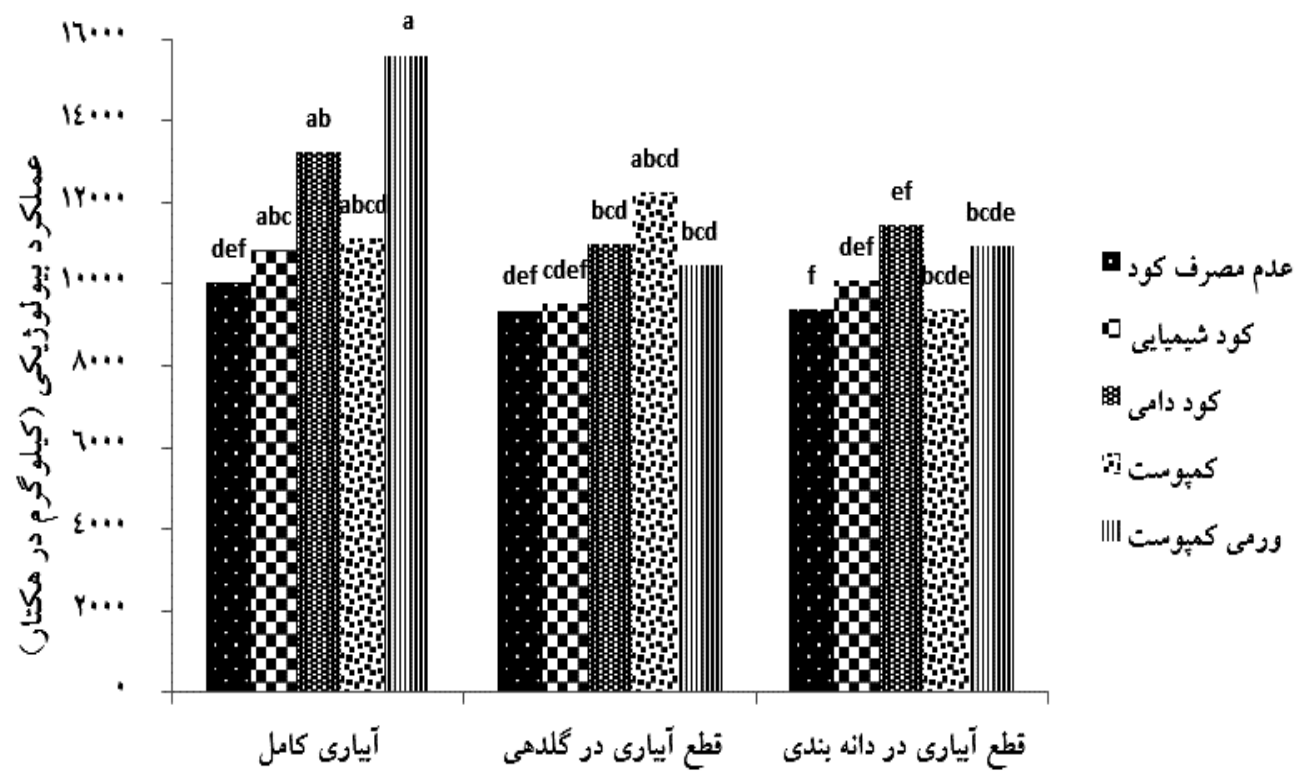

شكل r. برهم كنش تيمارهاى تنش خشكى و كودى بر عملكرد بيولوزيكى ارزن. ستونهاى داراى حروف مشابه نشاندهنده عدم وجود اختلاف معنى دار در سطح احتمال ينج درصد هستند (آزمون بSD)

داشته و بين دو تيمار از نظر آمارى اختلاف معنىدارى مشـاهده

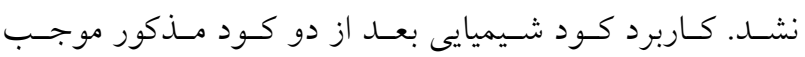
بيشترين افزايش اين صفت نسبت به ساير تيمارها شد (جـدول

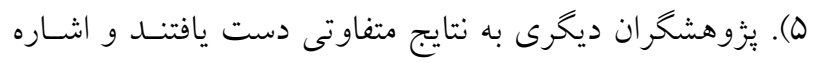

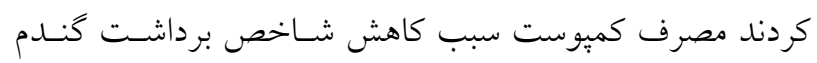

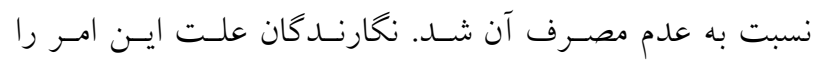

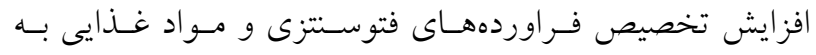
اندامهاى رويشى در مقايسـه بـا انــامهـاى زايشـى و درنتيجـهـ

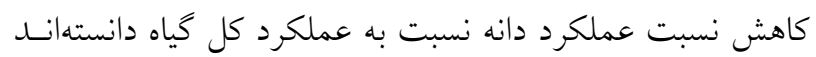

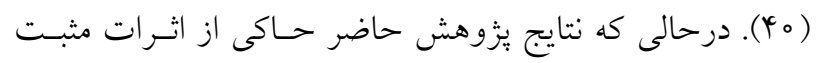
كميوست و ورمى كميوست بر هر دو فاز رويشى و زايشى كيـاه ارزن و بلويزه عملكرد دانه اين گياه بود.

$$
\text { كارايى مصرف آب }
$$

نتايج تجزيه واريانس نشاندهنده اثر معنىدار تيمارهاى آزمايش

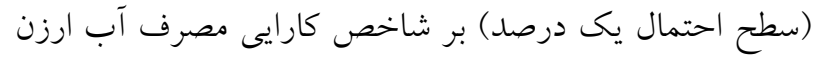

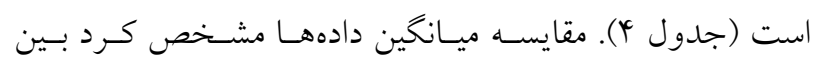

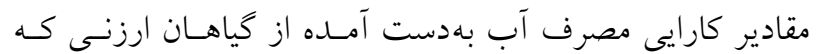

شاخص برداشت

تجزيه آمارى دادههاى بهدست آمسـه از شـاخص برداشــت ارزن

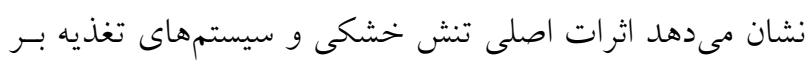

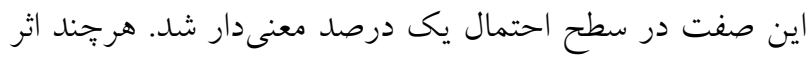
متقابل تنش خشكى و كود از نظر آمارى معنى دار نبود (جــدول

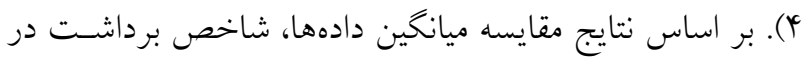

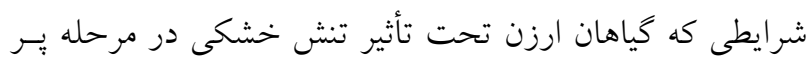

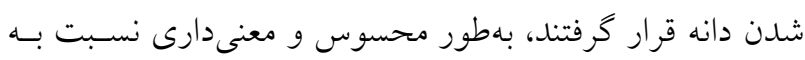

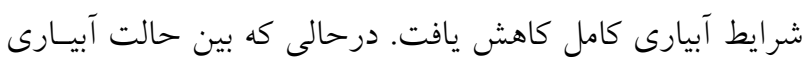

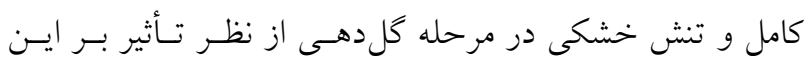

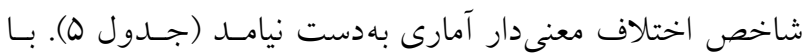

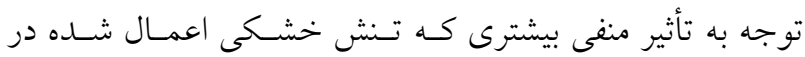
مرحله ير شدن دانه نسبت به مرحله گل دهى بـر عملكـرد دانسه

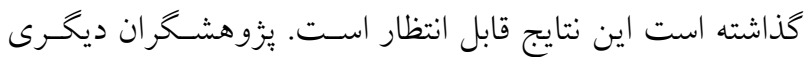
نيز بيان كردند بيشترين كاهش شاخص برداشت كندم در شرايط اعمال تنش در مرحله بعد از گلدهى اتفاق افتاد (Y).

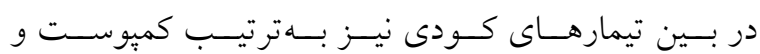

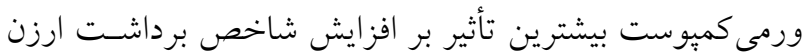


اين شاخص قرار كرفت و كمتـرين ميـزان (VQ/ كيلسوكرم بـر

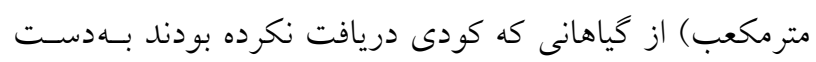

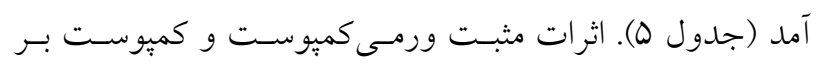

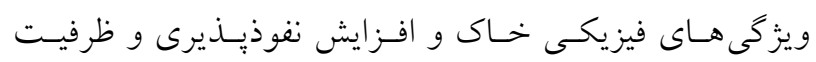

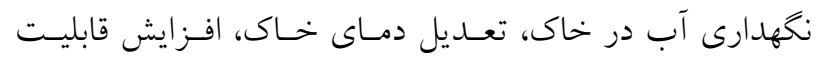

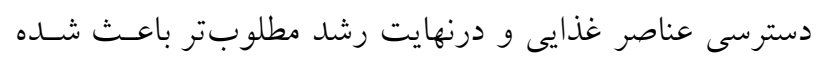

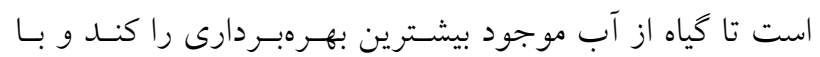

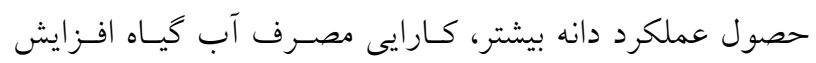
نشان دهد (1). به نظر مىرسد كميوست بيشترين نقش خهود را

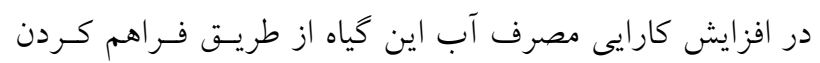

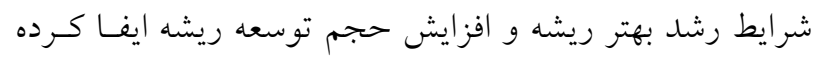

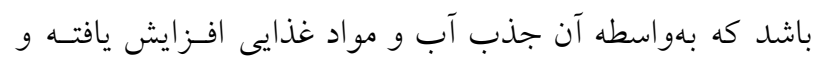

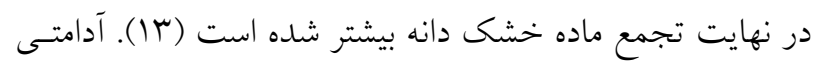

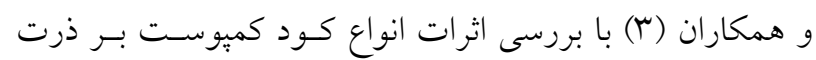

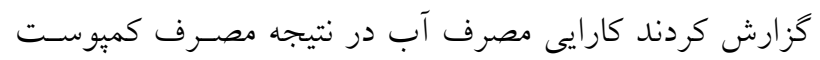

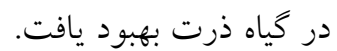

\section{نتيجه گيرى}

نتايج اين آزمايش مشخص كرد بــروز تسنش خشـكى در مراحسل

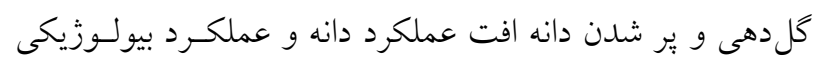

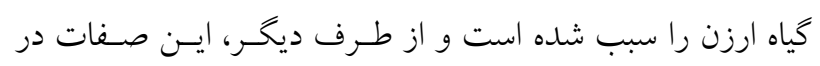

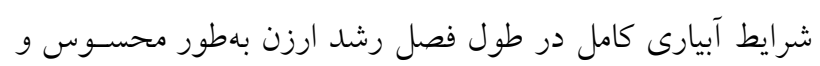

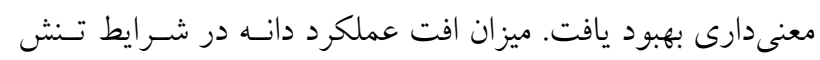

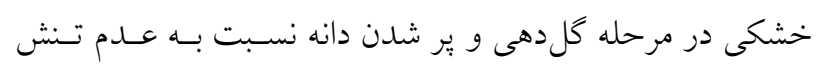

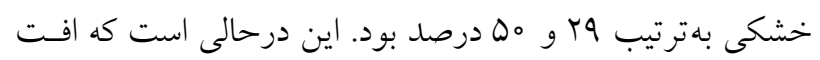
عملكرد بيولوزيكى رخ داده در شرايط مذكور بهترتيب معسادل 19

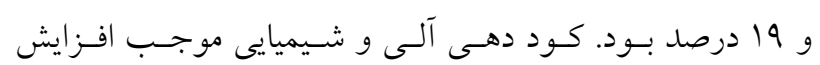

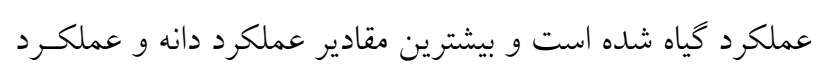

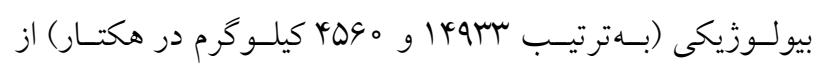

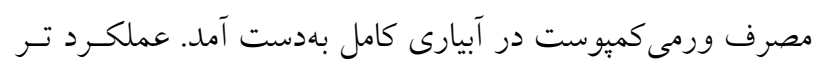

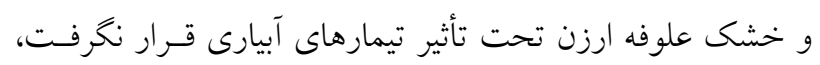

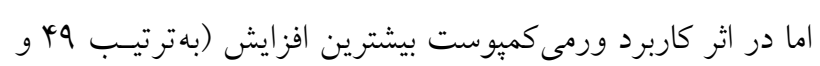

تحت آبيارى كامل قرار داشتند و گياهانى كه در مرحله گل دهى،

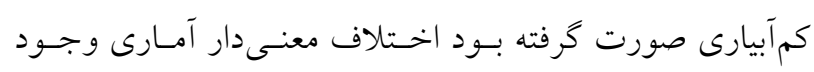

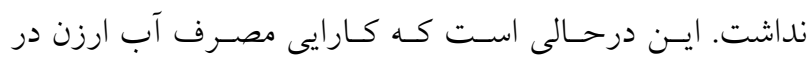

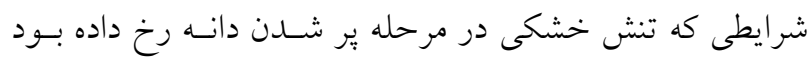

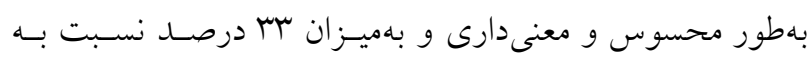

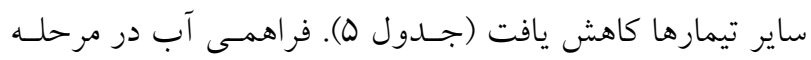

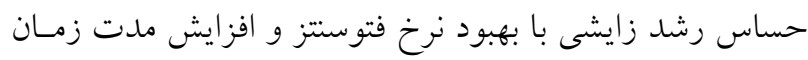

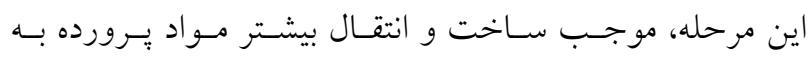

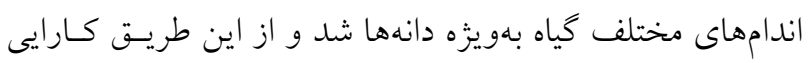

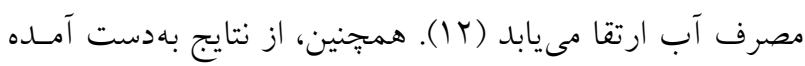

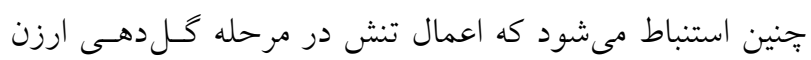

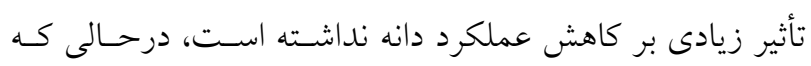

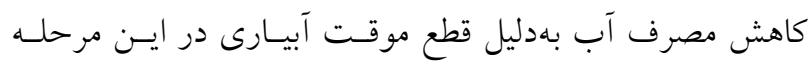
موجب صرفهجويى در مصرف آب و درنهايست بهبـود رانـدمان مصرف آب در اين كياه متحمل به خشكى شعى شده است. بهعـلاوه،

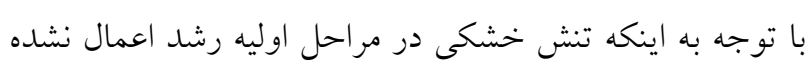

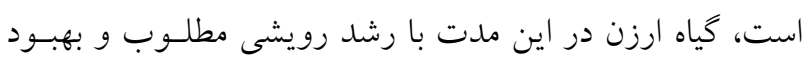

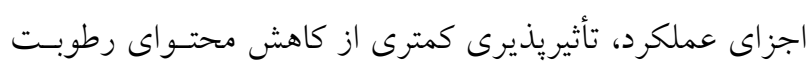

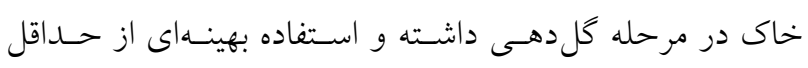

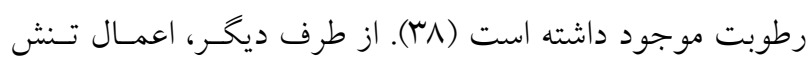
خشكى در مرحله ير شدن دانه با تأثير بر سرعت و ميزان انتقال

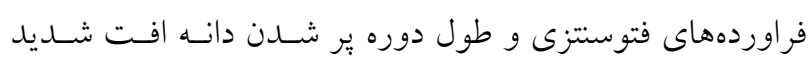

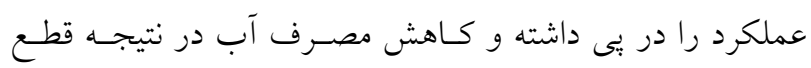

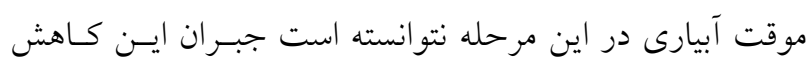

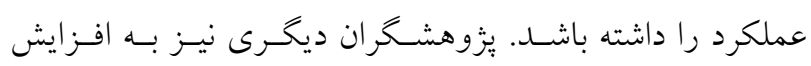

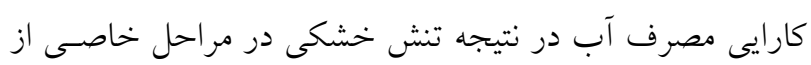

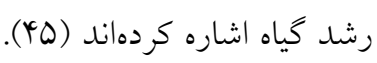

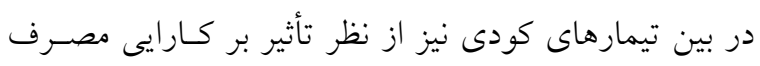

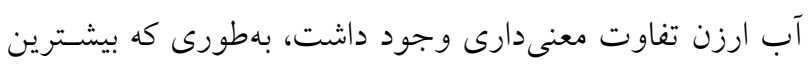

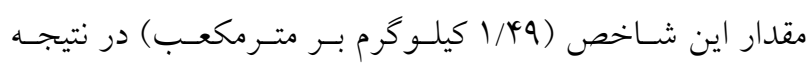

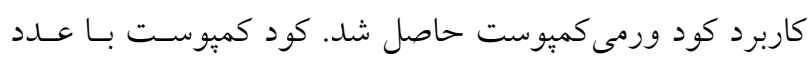

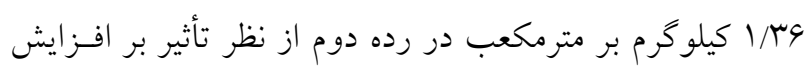




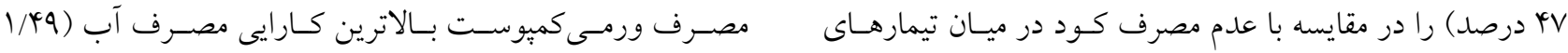

$$
\begin{aligned}
& \text { كودى نشان داد. شاخص برداشت و كارايى مصسرف آب ارزن در كيلوگرم بر مترمكعب) را در بين تيمارهاى كودى حاصل كرد. بـر }
\end{aligned}
$$

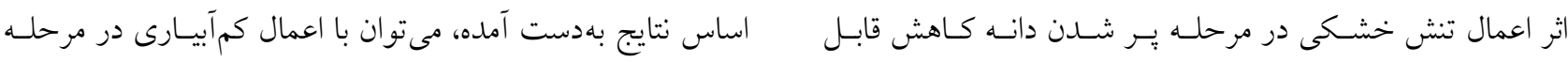

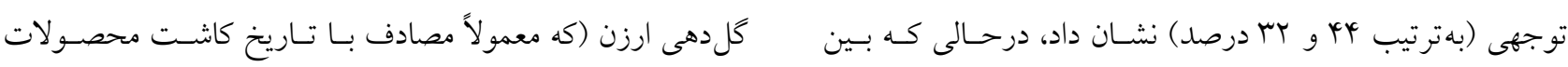

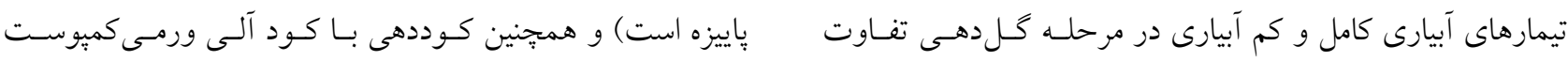

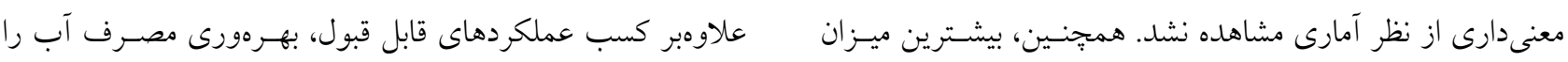

$$
\begin{aligned}
& \text { شاخص برداشت (9 دورصد) از كاربرد كميوست بهدست آمــد و ارتقا داد. }
\end{aligned}
$$

\section{منابع مورد استفاده}

1. Abbasi, M. and N. Najafi, N. 2011. The effect of soil moisture conditions, sewage sludge and chemical fertilizers on water use efficiency of rice. In: Proceedings of the $1^{\text {th }}$ Congress of Modern Agricultural Sciences and Technologies. Zanjan University. Zanjan, Iran. (In Farsi).

2. Abid, M., Z. Tian, S. T. Ata-U1-Karim, Y. Liu, Y. Cui, R. Zahoor, D. Jiang and T. Dai. 2016. Improved tolerance to post-anthesis drought stress by pre-drought priming at vegetative stages in drought-tolerant and -sensitive wheat cultivars. Plant Physiology and Biochemistry 106: 218-227.

3. Adamtey, N., O. Cofie, K. Ofosu-Budu, J. Ofosu-Anim, K. Laryea and D. Forster. 2010. Effect of N-enriched cocompost on transpiration efficiency and water-use efficiency of maize (Zea mays L.) under controlled irrigation. Agricultural Water Management 97(7): 995-1005.

4. Ahmadinezhad, R., N. Najafi, N. Aliasgharzad and S. H. Oustan. 2013. Effects of organic and nitrogen fertilizers on water use efficiency, yield and the growth characteristics of wheat (Triticum aestivum cv. Alvand). Water and Soil Science 23(2): 177-194.

5. Arancon, N., C. A. Edwards, P. Bierman, C. Welch and J. D. Metzger. 2004. Influence of vermicomposts on field strawberries. I: Effects on growth and yields. Bioresearch Technology 93: 145-153.

6. Arazmjoo, A., M. Heidari and A. Ghanbari. 2010. The effect of water stress and three sources of fertilizers on flower yield, physiological parameters and nutrient uptake in chamomile (Matricaria chamomilla L.). Iranian Journal of Medicinal and Aromatic Plants 25(4): 482-494. (In Farsi).

7. Backhaus, S., J. Kreyling, K. Grant, C. Beierkuhnlein, J. Walter and A. Jentsch. 2014. Recurrent mild drought events increase resistance toward extreme drought stress. Ecosystems 17: 1068-1081.

8. Bruck, H., W. A. Payne and B. Sattelmacher. 2000. Effects of phosphorus and water supply on yield, transpiration, water use efficiency and carbon isotope discrimination of pearl millet. Crop Science 40: 120-125.

9. Eriksen, G. N. and F. J. Coale. 1999. Soil nitrogen dynamics and maize production in municipal solid waste amended soil. Agronomy Journal 91:1009-1016.

10. Esmaeilian, Y., M. Galavi, E. Amiri and M. Heidari. 2014. Effect of organic and chemical fertilizers on yield, yield components and seed quality of sunflower under drought stress conditions. Water and Soil Science 24(3): 175-189. (In Farsi).

11. Farooq, M., A. Wahid, S. M. A. Basra and I. Din. 2009. Improving water relations and gas exchange with brassino steroids in rice under drought stress. Journal of Agronomy and Crop Science 195(4): 262-269.

12. Farooq, M., A. Wahid, N. Kobayashi, D. Fujita and S. M. A. Basra. 2009. Plant drought stress: effects, mechanisms and management. Agronomy for Sustainable Development 29: 185-212.

13. Fatma, A. G., A. M. Lobna and N. M. Osman. 2008. Effect of compost and bio-fertilizers on growth, yield and essential oil of sweet marjoram (Majorana hortensis) plant. International Journal of Agriculture and Biology 10(4): 381-387.

14. Fukai, S. and M. Cooper. 1995. Development of drought-resistant cultivars using physiomorphological traits in rice. Field Crops Research 40: 67-86.

15. Galmes, J., J. Flexas, R. Save and H. Medrano. 2007. Water relations and stomatal characteristics of Mediterranean plants with different growth forms and leaf habits: responses to water stress and recovery. Plant and Soil 290: 139-155.

16. Habibi, S. and M. Majidian. 2014. Effect of different levels of nitrogen fertilizer and vermicompost on yield and quality of sweet corn (Zea mays Hybrid Chase). Journal of Crop Production and Processing 4(11): 15-25. (In Farsi). 
17. Heydari, M., H. Nadian, A. M. Bakhshandeh, K. Alami Saeid and G. Fathi. 2008. Study the effects of different levels of salinity and nitrogen on osmotic adjustments and nutrients absorption in wheat. Journal of Science and Technology of Agriculture and Natural Resources 40: 193-210. (In Farsi).

18. Hussaini, M. A., V. B. Ogunlela, A. A. Ramalan and A. M. Falaki. 2008. Mineral composition of dry season maize (Zea mays L.) in response to varying levels of nitrogen, phosphorus and irrigation at Kadawa, Nigeria. World Journal of Agricultural Sciences 4(6): 775-780.

19. Jaleel, C. A., P. Manivannan, A. Kishorekumar, B. Sankar, R. Gopi, R. Somasundaram and R. Panneerselvam. 2007. Alterations in osmoregulation, antioxidant enzymes and indole alkaloid levels in Catharanthus roseus exposed to water deficit. Colloids and Surfaces B: Biointerfaces 45: 115-121.

20. Jaleel, C. A., B. Sankar, P. V. Murali, M. Gomathinayagam, G. M. A. Lakshmanan and R. Panneerselvam. 2008. Water deficit stress effects on reactive oxygen metabolism in Catharanthus roseus; Impacts on ajmalicine accumulation. Colloids and Surfaces B: Biointerfaces 62: 105-111.

21. Jamieson, P. 1995: Drought effects on biomass production and radiation-use efficiency in barley. Field Crops Research 43: 77-89.

22. Kumawat, P. D., N. L. Jat and S. S. Yadavi. 2006. Effect of organic manure and nitrogen fertilization on growth, yield and economics of barley (Hordeum vulgare). Indian Journal of Agriculture Science 76: 226-229.

23. Lafond, G. P. 1994. Effects of row spacing, seeding rate and nitrogen on yield of barley and wheat under zero- till management. Canadian Journal of Plant Science 74: 703-711.

24. Liang, Y., M. Nicolic, Y. Peng, W. Chen and Y. Jiang. 2005. Organic manure stimulates biological activity and barley growth in soil subject to secondary salinization. Soil Biology \& Biochemistry 37: 1185-1195

25. Loongenecker, S. R., J. Jones and R. K. Crookston. 2009. Effect of water deficit during grain filling on the pattern of maize kernel growth and development. Crop Science 27: 726-730.

26. Marschner, H. 1995. Mineral Nutrition of Higher Plants. $2^{\text {nd }}$ Edition. Academic Press, London.

27. Mostajeran, A. and V. Rahimi-Eichi. 2008. Drought stress effects on root anatomical characteristics of rice cultivars (Oryza sativa L.). Pakistan Journal of Biological Science 11(18): 2173-2183.

28. Nakano, H., S. Morita, I. Hattori and S. Kenji. 2008. Effects of planting time and cultivar on dry matter yield and estimated total digestible nutrient content of forage rice in southwestern Japan. Field Crops Research 105: 116-123.

29. Namarvari, M., G. A. Fathi, A. M. Bakhshandeh, M. H. Gharineh and S. Jafari. 2012. Effect of irrigation times and application of chemical and organic fertilizer on the morphology and yield of wheat var. Chamran. Agronomy Journal (Pajouhesh \& Sazandegi) 102: 110-117. (In Farsi).

30. Namarvari, M., G. A. Fathi, A. M. Bakhshandeh, M. H. Gharineh and S. Jafari. 2012. Interaction of terminal drought stress and organic fertilizers application on yield of bread wheat (Triticum aestivum). Journal of Crop Production and Processing 2(5): 163-172. (In Farsi).

31. Neisani, S., S. Fallah and F. Raiesi. 2012. The effect of poultry manure and urea on agronomic characters of forage maize under drought stress conditions. Journal of Agricultural Science and Sustainable Production 21(4): 63-75. (In Farsi).

32. Pantuwan, G., S. Fukai, M. Cooper, S. Rajatasereekul and J. C. O’Toole. 2002. Yield response of rice (Oryza sativa L.) genotypes to different types of drought under rainfed lowlands: part 1: Grain yield and yield components. Field Crops Research 73: 153-168.

33. Rashtbari, M. and H. A. Alikhani. 2012. Effect and efficiency of municipal solid waste compost and vermicompost on morpho-physiological properties and yield of canola under drought stress conditions. Journal of Agricultural Science and Sustainable Production 22(2): 113-127. (In Farsi).

34. Saini, H. S. and M. E. Westgate. 2000. Reproductive development in grain crops during drought. Advances in Agronomy 68: 59-96.

35. Sainju, U. M. and R. E. Good. 1993. Vertical rot distribution in relation to soil properties in New Jersey Pinelands forests. Plant Soil 150: 87-97.

36. Sainju, U. M., B. P. Singh and W. F. Whitehead. 2001. Comparison of the effects of cover crops and nitrogen fertilization on tomato yield, root growth, and soil properties. Scientia Hurticulturae 91: 201-214.

37. Sánchez-Díaz, M., J. L. García, M. C. Antolín and J. L. Araus. 2002. Effects of soil drought and atmospheric humidity on yield, gas exchange, and stable carbon isotope composition of barley. Photosynthetica 40: 415-421.

38. Sarabadani, R., M. R. Bihamta, Z. S Shobbar, M. Shahbazi, A. Karami, M. R. Naghavi, H. R. Nikkhah and H. Dehghani. 2014. The effect of late terminal drought stress on yield and many physiological characteristics in barley varieties and lines. Journal of Water Research in Agriculture 27(4): 535-549. (In Farsi).

39. Seghatoleslami, M. J., M. Kafi, I. Majidi, G. Nour-Mohammadi and F. Darvish. 2007. Effect of drought stress at different growth stages on yield and water use efficiency of five Proso millet (Panicum miliaceum) genotypes. Journal of Water and Soil Science 11(1): 215-227. (In Farsi).

40. Seyedi, M. and P. Rezvani Moghaddam. 2011. Evaluation of yield, yield components and nitrogen use efficiency in application of mushroom compost, biofertilizer and urea in wheat (Triticum aestivum L.). Journal of Agroecology 3: 
309-319. (In Farsi).

41. Suhane, R. K., R. K. Sinha and P. K. Singh. 2008. Vermicompost, cattle-dung compost and chemical fertilizers: Impacts on yield of wheat crops. Final Report. Communication of Rajendra Agricultural University. Pusa, Bihar, India.

42. Tartoura, A. H. 2010. Alleviation of oxidative-stress induced by drought through application of compost in wheat (Triticum aestivum L.) plants. American-Eurasian Journal of Agricultural \& Environmental Sciences 9(2): $208-216$.

43. Tasdighi, H., A. Salehi, M. Movahhedi Dehnavi and Y. Behzadi. 2015. Survey of yield, yield components and essential oil of matricaria chamomilla L. with application of vermicompost and different irrigation levels. Agricultural Science and Sustainable Production 25(3): 61-78. (In Farsi).

44. Vafaei Rostami, S. 2012. The effect of long time use of municipal waste compost and sewage sludge as alone and combined with chemical fertilizer on agronomic traits, yield, and nutrients accumulation in leaf and seed of soybean (Glycin max L.). BSc. Thesis. Sari University of Agriculture and Natural Resources, Sari, Iran. (In Farsi).

45. Wakarim, R., H. Aganchich, H. Tahi, R. Serraj and S. Wahabi. 2005. Comparative effects of PRD and regulated deficit irrigation on water relations and water use efficiency in common bean. Agriculture, Ecosystems \& Environment 106: 275-287.

46. Yadav, R. S., C. T. Hash, F. R. Bidinger and C. J. Howarth. 1999. Identification and utilization of quantitative trait loci to improve terminal drought tolerance in pearl millet (Pennisetum glaucum (L.) R. Br.). pp. 108-114, In: Ribaut, J. M. and D. Poland (ed.), Molecular Approaches for the Genetic Improvement of Cereals for Stable Production in Water- Limited Environments (Final Report). A Strategic Planning Workshop, Held at CIMMYT. El Batan, Mexico. 


\title{
The Effect of Organic and Chemical Nutrition Methods on Forage and Grain of Millet (Panicum miliaceum L.) under Terminal Drought Stress
}

\author{
Y. Esmaeilian ${ }^{1 *}$ \\ (Received: April 25-2018; Accepted: February 16-2019)
}

\begin{abstract}
Investigating the crop response to the deficit irrigation and evaluating the effect of drought stress on plant is one of the most important issues in crop production. In these circumstances, the use of organic fertilizers can play a mitigative role. Hence, an experiment was laid out as split plot based on randomized complete blocks design with three replications in Research Farm of University of Gonabad, Gonabad, east of Iran. The main factor comprised of full irrigation, temporary interruption of irrigation in the flowering stage, and temporary interruption of irrigation in the seed filling stage, and subfactor levels included of control, chemical fertilizer, manure, compost, and vermicompost. Drought stress led to decreases in grain and biological yield of the millet, and the highest yields were achieved by vermicompost application under full irrigation during the growth period. The forage yield, plant height, leaf number in the main stem, tiller number, and 1000 grain weight were not significantly affected by the drought stress. The forage, biological and grain yield showed the highest increase due to applying vermicompost, while the plant height and harvest index showed the highest increase when exposed to manure. Chemical fertilizer enhanced the tiller number to a greater value as compared to other treatments. The plants that were exposed to drought stress in the grain filling stage showed notable decreases in the harvest index. The water use efficiency of the plants exposed to drought stress in the flowering stage was increased, whereas in those exposed to drought stress in the grain filling stage it was decreased. Vermicompost and compost had the greatest positive influence on the water use efficiency. In general, even though the highest yields were obtained from full irrigation, with utilizing deficit irrigation operation in the flowering stage of millet we can improve the water use efficiency and the harvest index of this crop. In addition, the findings showed the positive effects of organic amendment in comparison with chemical amendment for millet cultivation.
\end{abstract}

Keywords: Chemical fertilizer, Compost, Irrigation, Vermicompost, Water use efficiency, Yield

1. Assistant Professor, Department of Agriculture and Natural Recourses, University of Gonabad, Gonabad, Iran.

*: Corresponding Author, Email: y.esmaeilian@gonabad.ac.ir 